\title{
MEDIDAS FRENTE AL INCUMPLIMIENTO DE LOS INSTRUMENTOS INTERNACIONALES EN MATERIA DE SUSTRACCIÓN INTERNACIONAL DE MENORES
}

\author{
REMEDIES FOR THE INFRINGMENT \\ OF THE INTERNATIONAL INSTRUMENTS REGARDING \\ THE INTERNATIONAL CHILD ABDUCTION
}

\author{
Rafael Arenas García \\ Catedrático de Derecho internacional privado \\ Universitat Autònoma de Barcelona
}

Recibido: 14.07.2021 / Aceptado: 24.07.2021

DOI: https://doi.org/10.20318/cdt.2021.6250

\begin{abstract}
Resumen: El Convenio de La Haya de 1980 y los Reglamentos 2201/2003 y 2019/1111 ofrecen soluciones para los casos de sustracción internacional de menores; ahora bien, cuando se produce un incumplimiento de estos instrumentos se carece de mecanismos eficaces para restaurar los derechos de niños, progenitores y demás personas implicadas.

En este trabajo se analizan las causas de esas dificultades y los diferentes mecanismos a los que se puede acudir para conseguir la correcta aplicación de estos instrumentos $\mathrm{y}$, en su caso, la declaración del incumplimiento. Se consideran tanto los mecanismos basados en la comunicación entre autoridades, guías y recomendaciones como la posibilidad de acudir al TEDH, así como otras vías reguladas por el Derecho internacional público.

Palabras clave: Sustracción internacional de menores, interés superior del menor, CEDH, responsabilidad internacional del estado.

Abstract: The 1980 Hague Convention and Regulations 2201/2003 and 2019/1111 offer solutions for cases of international child abduction. However, when there is a breach of these instruments, there is a lack of effective mechanisms to restore the rights of children, parents and other people involved.

This work analyses the causes of these difficulties and the different mechanisms that can be used to achieve the correct application of these instruments and, where appropriate, the declaration of noncompliance. Mechanisms based on communication between authorities, guides and recommendations, as well as the possibility of going to the ECHR, as well as other channels regulated by public international law, are considered.
\end{abstract}

Keywords: International child abduction, best interests of the minor, ECHR, international State responsibility.

Sumario: I. Introducción. II. Instrumentos internacionales en relación a la sustracción internacional de menores: 1. La devolución del menor como principio. 2. Cooperación entre autoridades. 3. Relaciones estructurales. III. Convenio de La Haya de 1980: 1. El seguimiento de la aplicación del Convenio. 2. El recurso al Tribunal de Estrasburgo. 3. Otras medidas. IV. Reglamentos de la UE: 1. El papel de la Comisión Europea, otras instituciones y los estados. 2. El papel del Tribunal de Luxemburgo. 3. El papel del Tribunal de Estrasburgo. V. Conclusión. 


\section{Introducción}

1. En el verano de 2019, un niño de 14 años se desplaza desde Barcelona, donde reside con su madre, a Dinamarca, el país de su nacionalidad y donde viven algunos familiares. El plan es pasar unas semanas de colonias y regresar a Barcelona una vez concluidas las vacaciones. Llega el mes de septiembre y el regreso del niño (a quien llamaremos N.) se retrasa. Su madre, también danesa y residente en Barcelona, averigua que aprovechando la estancia en Dinamarca algunos familiares suyos, con los que mantiene una relación distante, han contactado con el niño, se han dirigido a los servicios sociales daneses y han solicitado que el menor se quede en Dinamarca. Ante esta situación, la madre (a quien llamaremos S.) decide poner en marcha los mecanismos del convenio de La Haya de 1980 sobre sustracción internacional de menores ${ }^{1}$. Se dirige a la Autoridad Central española y le pide que solicite a la autoridad central danesa que ordene la devolución del menor. El 21 de noviembre de 2019, se envía a Dinamarca el requerimiento de la autoridad central española.

Las autoridades danesas, en vez de poner en marcha los mecanismos previstos en el convenio de La Haya para la devolución del menor, deciden que se pronunciarán sobre la custodia del menor y, una vez resuelta esta, decidirían sobre el retorno. El resultado de lo anterior es que N. siguió en Dinamarca y cuando en 2021 cumplió 16 años de edad dejó de ser posible obtener su regreso mediante los mecanismos previstos en el convenio de La Haya de $1980^{2}$.

2. El anterior es un caso real que muestra las dificultades que existen para resolver de manera adecuada los supuestos de sustracción internacional de menores. Los textos existentes diseñan un sistema de cooperación entre autoridades que debería permitir una resolución relativamente sencilla de los casos de sustracción, consiguiendo el regreso del menor a su estado de origen en un plazo breve, lo que limita las dificultades que se derivan del desarraigo respecto al país de la residencia original. La realidad, sin embargo, es que no en todos los casos es posible dicho regreso; obteniéndose el mismo en menos de la mitad de las sustracciones reportadas ${ }^{3}$. Obviamente, la devolución del menor no debe producirse en aquellos supuestos en los que se da alguna de las circunstancias que justifican la retención del menor de acuerdo con los instrumentos internacionales aplicables; pero esto no excluye que pueda haber supuestos en los que se ha dado una mala aplicación de dichos instrumentos ${ }^{4}$. La existencia de divergencias

\footnotetext{
${ }^{1}$ Convenio de La Haya sobre los aspectos civiles de la sustracción internacional de menores de 25 de octubre de 1980 , BOE, 24-VIII-1987. Vid. la página sobre el Convenio en la web de la Conferencia de La Haya sobre Derecho internacional privado, https://www.hcch.net/en/instruments/conventions/specialised-sections/child-abduction.

${ }^{2}$ Que el menor cumpla 16 años impide, incluso, la ejecución de la medida de retorno adoptada antes de que el niño tuviera dicha edad, vid. P. JimÉNEz Blanco, Litigios sobre la custodia y sustracción internacional de menores, Madrid/Barcelona/Buenos Aires, Marcial Pons, 2008, p. 97, n. núm. 188; A.-L. Calvo Caravaca/J. Carrascosa González, "Protección de menores", en A.-L. Calvo Caravaca/J. Carrascosa González (dirs.), Tratado de Derecho Internacional Privado, Valencia, Tirant lo Blanch, 2020, t. II, pp. 2013-2210, p. 2132.

${ }^{3}$ Vid. N. Lowe/V. Stephens, "The Seventh Meeting of the Special Commission on the Practical Operation of the 1980 Hague Child Abduction Convention and the 1996 Hague Child Protection Convention - October 2017”, https://assets.hcch. net/docs/d0b285f1-5f59-41a6-ad83-8b5cf7a784ce.pdf, p. 3, núm. 13. Vid. también las consideraciones sobre esta cuestión en R. Arenas García, "Construyendo la confianza mutua”, en E. Pérez Vera/J.C., Fernández Rozas/M. GuzmÁn Zapater/A. FerNÁNDEZ Pérez/M. GuZmán Peces (eds.), El Derecho internacional privado entre la tradición y la innovación. Libro homenaje al profesor doctor José María Espinar Vicente, Madrid, Iprolex, 2020, pp. 139-157, pp. 146-147.

${ }^{4}$ De ahí la importancia de las comisiones sobre la aplicación de los instrumentos internacionales, sobre las que volveremos un poco más adelante. En el caso del Convenio de La Haya de 1980 sobre sustracción internacional de menores, la comisión se ha reunido siete veces. Puede accederse a los documentos de las reuniones en la página web de la Conferencia (https://www. hcch.net/en/instruments/conventions/publications1/?dtid=57\&cid=24). Vid. también las notas sobre las reuniones publicadas en la REDI: A. Borrás Rodríguez, "Comisión especial de octubre de 1990 sobre el funcionamiento del Convenio de La Haya de 25 de octubre de 1980 sobre los aspectos civiles de la sustracción internacional de menores”, REDI, 1990, vol. XLII, núm. 1, pp. 289-290; id., "Conferencia de La Haya de Derecho internacional privado: comisión especial sobre la aplicación del Convenio de 1980 sobre sustracción internacional de menores (La Haya, 18-21 de enero de 1993), ibid., 1993, vol. XLV, núm. 2, pp. 645-647; id., "Conferencia de La Haya de Derecho internacional privado: tercera reunión de la comisión especial sobre la aplicación del Convenio de La Haya de 1980 sobre sustracción internacional de menores (17 a 21 de marzo de 1997)", ibid., 1997, vol. XLIX, núm. 1, pp. 348-350; E. Pérez Vera, "Conferencia de La Haya de Derecho internacional privado: cuarta reunión de la Comisión Especial sobre la aplicación del Convenio de La Haya de 1980 sobre Aspectos Civiles de la sustracción
} 
en la interpretación del instrumento, especialmente en lo que se refiere a las excepciones de retorno dificulta la aplicación del convenio ${ }^{5}$ y será necesario determinar en qué casos estamos ante discrepancias vinculadas a la diversidad de los sistemas judiciales implicados y en qué casos se puede afirmar que nos hallamos ante una mala interpretación o aplicación del instrumento.

El objeto de este trabajo es examinar qué actuaciones pueden seguirse cuando se produce una mala aplicación de los instrumentos en materia de sustracción de menores. El punto de partida es que el proceso ha agotado los recursos posibles dentro del estado (usualmente el estado al que fue desplazado el menor y que, por tanto, tendría la obligación de ordenar el retorno del mismo a su país de origen) y la parte o las partes que se ven perjudicadas por la mala aplicación del instrumento intentan conseguir una declaración, condena o satisfacción derivada de dicho incumplimiento. A partir de aquí se examinarán esas posibilidades teniendo en cuenta las vías abiertas ante tribunales internacionales y otros mecanismos de sanción para el estado incumplidor.

3. El estudio de estos "remedios" internacionales ante el incumplimiento de los instrumentos internacional en materia de sustracción internacional de menores se enfrenta a la dificultad de que la determinación de si efectivamente se ha producido o no el incumplimiento no es objetivable. Esto es, previsiblemente el estado al que ha sido desplazado el menor (por fijarnos en el supuesto más habitual, aunque no único) entenderá que ha actuado correctamente y que es solamente una percepción subjetiva de la parte afectada la de que se ha producido un incumplimiento. Como sabemos, el carácter eminentemente subjetivo del Derecho conduce a que en cualquier caso sea posible mantener opiniones diversas sobre la valoración jurídica que corresponde hacer; por lo que resulta esencial la determinación del sujeto que habrá de decidir entre las distintas opciones existentes ${ }^{6}$. Si nos limitamos a los casos internos, será el juez, y más específicamente, los jueces de última instancia, los que realizarán una concreción autorizada de los mandatos jurídicos que se considerará como correcta no porque podamos determinar que objetivamente lo sea; sino porque por convención se asume que esa concreción que realizan los jueces es la que pone fin al conflicto ${ }^{7}$.

En el ámbito internacional, en determinados casos es posible que un tribunal extienda a un nivel supraestatal la verificación de la corrección en la aplicación del Derecho, aunque, como veremos, siempre será necesario introducir algunos matices en relación a la función que ejercen los tribunales internos. Fuera de las jurisdicciones internacionales los mecanismos que pueden utilizarse tendrán siempre en cuenta esta imposibilidad de objetivación, lo que conducirá a que en vez de plantear los posibles incumplimientos como infracciones prefiera hablarse de "problemas" o "dificultades", tal como tendremos ocasión de examinar con algo más detenimiento cuando nos ocupemos de algunos de los mecanismos existentes en el marco de la Conferencia de La Haya de Derecho internacional privado ${ }^{8}$.

4. A continuación, en primer lugar, presentaremos los mecanismos que prevén los instrumentos internacionales para conseguir la devolución de los menores que han sido objeto de un traslado o reten-

internacional de menores (22 a 28 de marzo de 2001)”, ibid., 2001, vol. LIII, núms. 1 y 2, pp. 717-722; A. BorrÁs RodríGUEZ, "Comisión especial sobre el funcionamiento práctico del Convenio de La Haya de 1980 sobre sustracción de menores", ibid., 2006, vol. LVIII, núm. 2, pp. 1110-1116; id., "Reunión de la Comisión especial sobre el funcionamiento práctico del Convenio de La Haya de 1980 sobre sustracción internacional de menores y del Convenio de La Haya de 1996 sobre protección de niños (1 a 10 de junio de 2011)", ibid., 2011, vol. LXIII, núm. 2, pp. 314-320; id., "Reunión de la Comisión especial sobre el funcionamiento práctico del Convenio de La Haya de 1980 sobre sustracción internacional de menores y del Convenio de La Haya de 1996 sobre protección de niños, $2^{\mathrm{a}}$ parte (25 a 31 de enero de 2012), ibid., 2012, vol. LXIV, núm. 2, pp. 308-312

${ }^{5} \mathrm{Vid}$. por ejemplo, E. Pérez Vera, “Conferencia de La Haya...”, loc. cit., p. 721. Vid. L.J. Silberman, "Co-operative efforts in Private International Law on behalf of children: The Hague Children's Conventions", $R$. des C., 2006, t. 323, pp. 261-478, pp. 321-324 sobre algunas dificultades en la aplicación del convenio y sobre las diferencias en dicha aplicación en unos y otros estados. En relación al tema de la concreción de la residencia del menor, un concepto clave en la arquitectura del convenio, ibídem, pp. 346-355.

${ }^{6}$ Sin que necesariamente su criterio sea objetivamente "mejor". Vid. J.L. REQUEJO PAGÉs, Jurisdicción e independencia judicial, Madrid, Centro de Estudios Constitucionales, 1989, pp. 118-119.

${ }^{7}$ Vid. J.L. RequeJo PAgÉs, op. cit., pp. 72-75. De hecho, esta idea puede servir para caracterizar la función jurisdiccional, ibídem., pp. 90-91.

${ }^{8}$ Vid. L.J. Silberman, loc. cit., pp. 383-389. 
ción ilícitos. Tras ello examinaremos los mecanismos que cabe utilizar en los casos de mal funcionamiento de dichos instrumentos, centrándonos en el Convenio de La Haya de 1980 y en los Reglamentos de la UE. Esto nos permitirá valorar la eficacia de las medidas existentes para los casos de incumplimiento de los instrumentos relevantes y formular algunas conclusiones.

El eje de la exposición serán el ya mencionado Convenio de La Haya de 1980 y los Reglamentos de la UE; en la actualidad el Reglamento $2201 / 2003^{9}$ y en un futuro inmediato el Reglamento 2019/1111 ${ }^{10}$; pero será necesario considerar otros instrumentos que tienen una relación directa con la resolución de los casos de sustracción. Así, en particular, el Convenio de La Haya de 1996 sobre protección de menores ${ }^{11}$. No puede dejar de señalarse, sin embargo, la existencia de otros instrumentos que han tenido una práctica menor ${ }^{12}$.

\section{Instrumentos internacionales en relación a la sustracción internacional de menores}

\section{La devolución del menor como principio}

5. El Convenio de La Haya de 1980 descansa sobre un mecanismo de gran sencillez en su formulación inicial: la devolución del menor al Estado de su residencia con anterioridad al traslado ilícito (art. 12). El Informe Explicativo del Convenio ${ }^{13}$ indica con claridad que el objetivo del Convenio es desincentivar el traslado ilícito del menor por la vía de negar eficacia a dicho traslado al obligar a las autoridades a restaurar el status quo anterior al traslado del menor ${ }^{14}$ y no existe discusión sobre la relevancia de este principio de devolución del menor como base de la regulación ${ }^{15}$. La idea, sobre la que tendremos que volver, es la de que si la sustracción pretende que el sustractor obtenga alguna ventaja en relación a la custodia del menor, lo que se hace necesario es devolver la situación al punto en el que se encontraba antes de la sustracción. Esta aproximación ha conducido a que se califique al convenio como "fáctico"16, ya que su objetivo no es resolver sobre a cuál de los progenitores le ha de corresponder ejercer la custodia o sobre su régimen; sino que se debería limitar a poner fin a la sustracción para evitar que ésta incida en la determinación de esa custodia o este régimen. Tal como veremos, existen, sin embargo, algunas dificultades para un acercamiento maximalista a este propósito.

\footnotetext{
${ }^{9}$ Reglamento (CE) no 2201/2003 del Consejo, de 27 de noviembre de 2003, relativo a la competencia, el reconocimiento y la ejecución de resoluciones judiciales en materia matrimonial y de responsabilidad parental, por el que se deroga el Reglamento $(\mathrm{CE}) \mathrm{n}^{\mathrm{o}} 1347 / 2000, D O$, núm. L 338, de 23 de diciembre de 2003

${ }^{10}$ Reglamento (UE) 2019/1111 del Consejo de 25 de junio de 2019 relativo a la competencia, el reconocimiento y la ejecución de resoluciones en materia matrimonial y de responsabilidad parental, y sobre la sustracción internacional de menores, DO, núm. L 178, de 2 de julio de 2019. De acuerdo con lo previsto en su art. 105, este Reglamento comenzará a aplicarse a partir del 1 de agosto de 2022.

${ }^{11}$ Convenio relativo a la competencia, la ley aplicable, el reconocimiento, la ejecución y la cooperación en materia de responsabilidad parental y de medidas de protección de los niños, hecho en La Haya el 19 de octubre de 1996, BOE, 2-XII-2010. Vid. también la página sobre dicho Convenio en la web de la Conferencia de La Haya de DIPr, https://www.hcch.net/en/instruments/conventions/specialised-sections/child-protection. La relación entre ambos instrumentos había sido destacada desde la misma conclusión del Convenio de 1996 [vid. A. Borrás Rodríguez, "Conferencia de La Haya de Derecho internacional privado: tercera reunión...", loc. cit. (supra n. núm. 4), p. 350]; hasta el punto de que las comisiones de seguimiento en la Conferencia de La Haya acabaron siendo conjuntas para ambos instrumentos, vid. las referencias contenidas supra en la n. núm. 4.

${ }^{12}$ En particular, el Convenio Europeo sobre reconocimiento de medidas en materia de custodia de menores (Convenio Europeo relativo al reconocimiento y la ejecución de decisiones en materia de custodia de menores, así como al restablecimiento de dicha custodia, hecho en Luxemburgo el 20 de mayo de 1980, BOE, 1-IX-1984). Para una referencia a cómo trabajos anteriores ya podían incidir en la solución de los casos de sustracción internacional de menores vid. L.J. Silberman, loc. cit., p. 301.

${ }^{13}$ Elaborado por Elisa Pérez-Vera, puede leerse en la página web de la Conferencia de La Haya, https://assets.hcch.net/ docs/a5fb103c-2ceb-4d17-87e3-a7528a0d368c.pdf.

${ }^{14}$ E. Pérez Vera, "Informe Explicativo", loc. cit., p. 429.

${ }^{15}$ Vid. A. Grammaticaki-Alexion, "Best interest of the child in Private International Law", R. des C., 2020, t. 412, pp. 253434, p. 327; P. JiMÉNEZ Blanco, Litigios sobre la custodia y sustracción internacional de menores, Madrid/Barcelona/Buenos Aires, Marcial Pons, 2008, p. 12; A.-L. Calvo Caravaca/J. Carrascosa González, "Protección de menores", loc. cit., p. 2129.

16 A.-L. Calvo Caravaca/J. Carrascosa González, ibídem. Vid. también C.I. Cordero Álvarez, "Sustracción internacional de menores extracomunitaria: a vueltas con la obligación de restitución automática del Convenio de La Haya de 1980 en la práctica española", $C D T, 2021$, vol. 13, núm. 1, p. 136, https://e-revistas.uc3m.es/index.php/CDT/article/view/5955/4328.
} 
La aproximación del Convenio de La Haya de 1980 fue asumida por el Reglamento 2201/2003 ${ }^{17}$. En este Reglamento sobre responsabilidad parental se incluye una regulación de la sustracción internacional de menores complementaria del Convenio de La Haya de $1980^{18}$. Asumiendo la aplicación del Convenio en el caso de sustracción de menores entre Estados miembros del Reglamento, se introducen algunas exigencias específicas; en concreto, la de que se dé audiencia al menor ${ }^{19}$, la de que la decisión se dicte en un período máximo de seis semanas tras la interposición de la demanda ${ }^{20}$, limita la posibilidad de rechazar la restitución del menor (art. 11.4), se especifica que no puede adoptarse una decisión de no retorno sin escuchar a quien ha solicitado la restitución (art. 11.5), se especifican las obligaciones de comunicación a las autoridades de los otros estados y a los interesados (art. 11.6 y 7) y se recuerda que, sea cual sea la decisión sobre la restitución en el marco del Convenio de La Haya de 1980, cualquier resolución adoptada por la autoridad competente que ordene la restitución podrá ser ejecutada de acuerdo con lo previsto en el Reglamento ${ }^{21}$.

En coherencia con el principio de reconocimiento y confianza mutuas que inspiran, al menos en parte, el espacio europeo de libertad, seguridad y justicia, el Reglamento de la UE refuerza la obligación de confianza en las autoridades del estado al que ha de ser devuelto el menor, yendo más allá de lo que prevé el Convenio de La Haya y reduciendo, como se acaba de indicar, la posibilidad de rechazar la restitución. El Reglamento 2019/1111, que sustituye al 2201/2003 ${ }^{22}$, profundiza en esta necesidad de confianza, haciendo más difícil aún el mantenimiento del menor en el estado al que ha sido trasladado (o en el que es retenido) de manera ilícita ${ }^{23}$. De esta forma, la devolución del menor al estado en el que residía antes del traslado o retención ilícitos se afianza como clave en la gestión de este tipo de casos.

Lo anterior no quiere decir que no haya supuestos en los que deba negarse esta restitución. El art. 13 del Convenio de La Haya prevé varios en los que no existirá obligación de devolver al menor. Esto sucederá cuando la persona titular de la responsabilidad parental no ejercía de manera efectiva los

\footnotetext{
${ }^{17}$ Vid. supra n. núm. 9.

${ }^{18}$ Art. 11 del Reglamento. El art. 60 del Reglamento establece la primacía del Reglamento sobre el Convenio de La Haya de 1980 "en las relaciones entre los Estados miembros"; pero, en realidad, lo que encontramos es una complementariedad entre ambos instrumentos, vid. P. JiMÉNEZ BLANCO, op. cit., pp. 159-160; no exenta, sin embargo, de algún posible caso de contradicción entre ambos instrumentos (ibídem, p. 161). Vid. también A.-L. Calvo Caravaca/J. Carrascosa González, "Protección de menores", loc. cit., pp. 2168-2170. El art. 23 del Reglamento 2019/1111 (supra n. núm. 10) ya se refiere de forma explícita a esta complementariedad. Vid. su art. 22: "Los artículos 23 a 29 y el capítulo VI del presente Reglamento serán de aplicación y complementarán el Convenio de La Haya de 1980..." Con anterioridad al Reglamento 2201/2003, el Reglamento 1347/2000 [Reglamento (CE) $n^{\circ} 1347 / 2000$ del Consejo, de 29 de mayo de 2000, relativo a la competencia, el reconocimiento y la ejecución de resoluciones judiciales en materia matrimonial y de responsabilidad parental sobre los hijos comunes", $D O$, núm. L 160, de 30 de junio de 2000] ya se había establecido (art. 4) que "Los órganos jurisdiccionales competentes con arreglo al artículo 3 ejercerán su competencia de conformidad con lo dispuesto en el Convenio de La Haya, de 25 de octubre de 1980, sobre los aspectos civiles de la sustracción internacional de menores, y en particular en sus artículos 3 y 16".

${ }^{19}$ Art. 11.2 del Reglamento: "En caso de aplicarse los artículos 12 y 13 del Convenio de La Haya de 1980, se velará por que se dé al menor la posibilidad de audiencia durante el proceso, a menos que esto no se considere conveniente habida cuenta de su edad o grado de madurez".

${ }^{20}$ Art. 11.3 del Reglamento, que refuerza lo ya previsto en el art. 11 del Convenio de La Haya.

${ }^{21}$ Art. 11.8 del Reglamento. La referencia a que la decisión debe haber sido adoptada por una autoridad competente podría introducir alguna confusión, ya que el procedimiento de reconocimiento y ejecución del Reglamento no prevé ningún control de competencia indirecto y no hemos de interpretar que sí lo hace en este supuesto. De esta forma, la autoridad que adopte la decisión deberá determinar su competencia según lo establecido en el Reglamento, pero la autoridad de otro estado frente a la que se quiera hacer valer esta decisión no procederá a ningún control de competencia. Vid. sobre el reconocimiento de sentencias en materia de custodia cuando se ha producido una sustracción internacional del menor la STJ (Sala Cuarta) de 19 de noviembre de 2015, As. C-455/15 PPU, P y Q, ECLI:EU:C:2015:763; vid. sobre esta decisión C. M. CAAmiÑa Domínguez, "Orden público internacional y prohibición de control de competencia judicial internacional: Asunto C-455/15 PPU, P Y Q", CDT, 2017 , vol. 9, núm. 2, https://e-revistas.uc3m.es/index.php/CDT/article/view/3892/2448.

${ }^{22}$ Vid. supra n. núm. 10.

${ }^{23} \mathrm{Vid}$. S. BARTOLINI, "In the name of the best interests of the child: the principle of mutual trust in child abduction cases", CMLR, 2019, vol. 56, núm. 1, pp. 91-120; R. Arenas García, “Construyendo la confianza mutua”, en E. Pérez Vera/J.C. FernÁndez Rozas/M. Guzmán Zapater/A. Fernández Pérez/M. Guzmán Peces (eds.), El Derecho internacional privado entre la tradición y la innovación. Libro homenaje al profesor doctor José María Espinar Vicente, Madrid, Iprolex, 2020, pp. 139-157, pp. 152-155. Resulta también necesaria la consulta de la construcción general sobre la tutela de los derechos fundamentales en origen que realiza $\mathrm{M}^{\mathrm{a}} \mathrm{V}$. CUARTERo RuBio [Cooperación judicial civil en la Unión Europea y tutela en origen de Derechos Fundamentales, Cizur Menor (Navarra), Thomson Reuters/Aranzadi, 2020, esp. pp. 43-104.
} 
derechos de custodia en el momento de la sustracción o retención o había accedido a dicha sustracción o retención. También se podrá denegar la restitución cuando el regreso ponga al menor en un grave riesgo. También hay que tener en cuenta que la obligación de retorno opera en sus términos más estrictos cuando ha transcurrido menos de un año entre la sustracción y el inicio de los procedimientos en el estado al que ha sido desplazado o donde ha sido retenido (art. 12 del Convenio). Igualmente hay que tener en cuenta el punto de vista del menor cuando, de acuerdo con su grado de madurez, es adecuado tener en cuenta su opinión (art. 13 del Convenio). Estos mismos motivos de denegación de la devolución pueden operar cuando se apliquen los Reglamentos de la UE, aunque, tal como ya se ha indicado, en este caso no podrá apreciarse la existencia de un grave riesgo para el menor en caso de retorno si las autoridades del estado al que ha de ser devuelto el menor han adoptado medidas para evitar ese riesgo para el menor. La confianza que ha de regir entre las autoridades de distintos estados miembros de la UE exige que se limiten aquellos supuestos en los que puedan existir diferencias de criterio entre las autoridades de unos $\mathrm{y}$ otros estados miembros.

6. La restitución del menor, sin embargo, no está libre de problemas. Estos se plantean, sobre todo, en aquellos casos en los que dicha restitución no responde al interés superior del menor. Lo examinaremos brevemente a continuación.

Si la restitución del menor se ha convertido en la piedra angular en la regulación de la sustracción internacional de menores, el interés superior del menor es el eje sobre el que gira toda la normativa relativa a menores ${ }^{24}$; y la articulación entre la necesidad de restitución y la de garantizar el interés superior del menor no es siempre fácil. Así, hemos de preguntarnos si en cada caso responde al interés superior del niño la devolución al país del que ha sido sustraído y por qué, si no responde a dicho interés la restitución, ha de procederse a ella ${ }^{25}$. La jurisprudencia del Tribunal de Estrasburgo es aquí interesante, porque el TEDH ha establecido en ocasiones que se había vulnerado el derecho a la vida privada y familiar del menor al no haber valorado suficientemente los riesgos que podían derivarse para el menor de su devolución al estado de su residencia. La devolución no puede ser ordenada de forma automática o mecánica ${ }^{26}$; lo que obliga a interpretar los motivos de denegación de la restitución de una forma tal que permita dar satisfacción a los diferentes intereses contrapuestos ${ }^{27}$. Esto último resulta relevante para

${ }^{24}$ El concepto de "interés superior del niño" ya aparece en la Declaración de los Derechos del Niño de 20 de noviembre de 1959, A.G. res. 1386 (XIV), y es retomado por el Convenio sobre Derechos del Niño de 1989 (Convención sobre los Derechos del Niños, aprobada el 20 de noviembre de 1989 por la Asamblea General de las Naciones Unidas, BOE, 31-XII-1990; vid. P. Rodríguez Mateos, "La protección jurídica del menor en la Convención sobre los derechos del niño de 20 de noviembre de 1989”, REDI, 1992, vol. XLIV, núm. 2, pp. 465-498). Este Convenio ayudó a colocar el interés superior del niño (o del menor) en el centro de la regulación, tanto de Derecho internacional privado como de Derecho civil. Vid., por ejemplo, A. BorRÁs RoDRÍGUEZ, "El "interés del menor" como factor de progreso y unificación del derecho internacional privado", RJC, 1994, núm. 4, pp. 47-99, p. 56. Vid. también E. RoCA I TRIAS, “Contestación”, ibid., pp. 101-122, pp. 103-105 sobre las primeras referencias al interés del menor hasta llegar al Convenio de 1989. Vid. también E RodRíGuez PINEAu ("La oposición al retorno del menor secuestrado: movimientos en Bruselas y La Haya”, REEI, 2018, núm. 35, file://C:/Users/1003616/AppData/Local/Temp/04_Estudio_RODRIGUEZ_Elena.pdf, p. 6) quien destaca que el Convenio de La Haya de 1980 no hace todavía referencia al interés superior del menor. En una reinterpretación posterior, sin embargo, A. BORRÁs RoDRÍGUEZ ("El "interés superior del menor", loc. cit., p. 85) mantiene que es el interés superior del menor el que justifica la necesidad de su pronto retorno al país donde tenía su residencia antes de la sustracción porque ese interés exige la estabilidad del menor.

${ }^{25}$ Vid. A. Grammaticaki-Alexion, loc. cit., pp. 342 y ss. Recientemente, vid. Maa. Cuartero Rubio, "La sustracción internacional de menores ante el juez: a vueltas con la racionalidad del Convenio de La Haya de 1980 y la ponderación", en $\mathrm{M}^{\mathrm{a}} \mathrm{V}$. Cuartero Rubio/J.M. Velasco Retamosa (dirs.), La vida familiar internacional en una Europa compleja: cuestiones abiertas y problemas de la práctica, Valencia, Tirant lo Blanch, 2021 (en prensa), quien mantiene que la restitución se corresponde con el interés superior del menor, aunque dicho interés superior ha de ponderarse con el derecho a la vida familiar de las personas relacionadas con el menor y con el respeto a las garantías procesales. Entiendo que si bien como principio general lo que mejor se ajusta al interés del menor es la restitución en los supuestos de sustracción, lo que ha de determinarse es en cada caso concreto qué es lo que mejor responde a ese interés, pudiendo ser que en determinadas circunstancias ese interés exigiera la permanencia del menor en el país al que había sido desplazado.

${ }^{26}$ Vid. núm. 138 de la STEDH de 6 de julio de 2010, Neulinger y Shuruk v. Suiza (solicitud no 41615/07). Vid. también la STEDH de 26 de noviembre de 2013, X v. Letonia (solicitud nº 27853/09). Vid. en España la STC (Sala Segunda) 16/2016 de 1 de febrero, ECLI:ES:TC:2016:16. Vid. sobre esta sentencia C.M. CAAMIÑo DomínguEZ, "El interés superior del menor: la integración en el nuevo medio", $C D T, 2016$, vol. 8, núm. 2, https://e-revistas.uc3m.es/index.php/CDT/article/view/3254/1920.

${ }^{27}$ Lo que enlaza con la propuesta que realiza $\mathrm{M}^{\mathrm{a}} \mathrm{V}$. CUARTERo RuBio (loc. cit., esp. epígrafe IV). 
nuestro propósito, puesto que no podremos eludir esta consideración cuando se trate de valorar si se ha producido o no una vulneración del Convenio de La Haya; lo que será especialmente interesante cuando consideremos posibles remedios a esta vulneración que se ubican fuera del marco de la Conferencia de La Haya de DIPr.

En el caso de la UE, lo anterior tiene que ser matizado, ya que, tal y como se ha adelantado, las exigencias derivadas de la integración europea operan en un sentido diferente al que acabamos de ver. Aquí resulta especialmente relevante responder a las exigencias de la integración europea, que apuntan precisamente en la dirección de facilitar la restitución y reducir los motivos de no denegación. De esta forma, cuando se acuda a los mecanismos previstos en el Derecho de la UE nos podremos encontrar con exigencias contradictorias con las que resultan del Convenio Europeo de Derechos Humanos. Obviamente, tanto este último instrumento (y el sistema de garantías de los derechos fundamentales en el que se inserta) como el ordenamiento de la UE mantienen que no ha de existir contradicción entre las exigencias de uno y otro; pero será necesario precisar y matizar para que esta exigencia de principio se convierta en reglas y procedimientos que consigan, en cada concreto supuesto, conciliar las exigencias de todos los ordenamientos conectados con el caso.

\section{Cooperación entre autoridades}

7. La restitución de menores no puede operar sin una fluida comunicación entre autoridades de diferentes estados. Si la restitución del menor es el objetivo que da sentido tanto al Convenio de La Haya de 1980 como a los Reglamentos europeos, el mecanismo que permite llegar a ese objetivo es la cooperación entre autoridades ${ }^{28}$. Esta cooperación permite, por ejemplo, que la solicitud de restitución pueda ser presentada en el estado de la residencia del menor para que sea la autoridad central de dicho estado la que se dirija a la del estado al que ha sido desplazado el menor o donde ha sido retenido. La obligación de cooperación entre las autoridades centrales designadas en cada uno de los estados vinculados por el Convenio se concreta en su art. 7 e incluye el traspaso de la información necesaria para encontrar al menor y poder decidir sobre la restitución teniendo en cuenta sus circunstancias y el contexto legal. La cooperación entre autoridades también es necesaria para facilitar la consecución de una solución amistosa al caso. La información facilitada por las autoridades del estado de la residencia del menor, incluida su autoridad central, deberán ser tenidas en cuenta para la valoración, en su caso, de la decisión de no retornar al menor, tal y como nos recuerda el art. 13 del Convenio. La obligación de cooperación entre autoridades centrales también se extiende a las medidas en relación a los derechos de visita (art. 21 del Convenio).

Esta obligación de cooperación entre autoridades se refuerza en el Reglamento 2201/2003. Así, se prevé específicamente que en caso de dictarse una decisión de no restitución, dicha decisión deberá trasladarse de inmediato al órgano jurisdiccional competente o a la autoridad central del estado de residencia del menor con anterioridad al desplazamiento (art. 11.6), y el Reglamento 2019/111129 establece la posibilidad de comunicación directa entre autoridades, o por medio de las autoridades centrales, antes de decidir el no retorno del menor (art. 27.4 del Reglamento 2019/1111). Además, se prevé la comunicación entre autoridades en el caso de denegación de la restitución por apreciar que existe grave riesgo para el menor en caso de restitución o por atender a los deseos del menor (art. 29.3 del Reglamento 2019/1111). Tal como se ha avanzado, la lógica de los Reglamentos europeos es la de responder a la

\footnotetext{
${ }^{28}$ Vid., por ejemplo, Th. KRuger, International Child Abduction, Oxford/Portland (Oregon), 2011, pp. 113-114; J.C. FerNÁndez RozAs/S. SÁnchez LoREnzo, Derecho internacional privado, Cizur Menor (Navarra), Civitas/Thomson Reuters, $11^{\text {a }}$ ed. 2020, p. 431. Para una descripción del funcionamiento del mecanismo del Convenio nos remitimos a las obras generales existentes. En este sentido es especialmente útil la explicación gráfica que puede encontrarse en J.C. FERNÁNDEZ RoZAS/S. SÁNCHEZ LoRENZo, op. cit., pp. 435-437, tomada de la Guía práctica para la aplicación del nuevo Reglamento Bruselas II (Comisión/Red Judicial Europea, p. 38). Para el Reglamento Bruselas II bis, vid. la guía práctica para este Reglamento de la Dirección General de Justicia de la Comisión Europea (https://op.europa.eu/es/publication-detail/-/publication/f7d39509-3f10-4ae2-b99353ac6b9f93ed, pp. 49 y ss.. Vid. también A.-L. Calvo Caravaca/J. Carrascosa González, loc. cit., pp. 2143-2165 y $2167-2170$.

${ }^{29}$ Vid. supra n. núm. 10.
} 
confianza exigida entre autoridades de estados diferentes de la UE, lo que redundará en limitar las posibilidades de denegación de la restitución del menor.

8. Dado que el proceso de sustracción puede implicar a autoridades de estados diferentes; en principio y con mayor frecuencia, del estado de la residencia original del menor y del estado al que es desplazado o en el que es retenido, el incumplimiento del Convenio de La Haya de 1980 o de los Reglamentos europeos puede darse tanto en relación al estado al que ha sido desplazado el menor como en el estado en el que residía originalmente o en cualquier otro estado que tenga conexiones con el caso ${ }^{30}$. Así, en el caso de que el estado de la residencia original del menor no traslade a las autoridades de estado donde se encuentra el menor la solicitud de activación de los mecanismos previstos en el Convenio de La Haya (y a los que, como hemos visto, se remiten los Reglamentos de la UE).

En esta línea, si el proceso se dilata en el estado la que ha sido desplazado el menor sin que haya una decisión sobre la sustracción o se produce una decisión sobre la custodia cuando aún no existe un pronunciamiento sobre la devolución del menor se produce una infracción del Convenio o del Reglamento en dicho estado, pero que puede acabar afectando también a las autoridades del estado de la residencia del menor con anterioridad a la sustracción. Tenemos que fijarnos también en el caso en el que se produce una decisión sobre el fondo en el estado al que ha sido desplazado el menor antes de resolvers sobre la sustracción ${ }^{31}$. El art. 11 del Convenio de La Haya prevé que la autoridad central del estado requirente se dirija a la autoridad central del estado requerido para que ésta reclame una explicación de la autoridad judicial o administrativa competente. Además de esto, hemos de tener también en cuenta que el incumplimiento del Convenio de La Haya supone la vulneración de una obligación internacional frente a la que se pueden exigir responsabilidades por parte de los otros estados contratantes a través de los mecanismos pertinentes de Derecho internacional público. Es cierto que el incumplimiento de convenios de DIPr no suele implicar que se pongan en marcha los mecanismos propios de la responsabilidad estatal como sujeto de Derecho internacional; pero no hay nada que lo impida y, de hecho, se conoce algún caso en el que sí se pusieron en marcha estos mecanismos ${ }^{32}$. Es por eso que no resultaría imposible que se recurriera a los procedimientos propios del Derecho internacional público para exigir el cumplimiento de las obligaciones derivadas del Convenio de La Haya y también sería posible que se utilizaran los procedimientos propios del Derecho interno de los estados implicados en el caso para exigir a las autoridades de dicho estado que pusieran en marcha los mecanismos previstos en el Convenio para conseguir la devolución del menor. No será fácil, sin embargo, que estos mecanismos prosperen, pues el ámbito de las relaciones internacionales estará, en buena medida, incluido entre las materias en las que la administración goza de libertad para desarrollar sus políticas sin que nazcan derechos subjetivos de los particulares como consecuencia de la inacción de los poderes públicos. Será, en cualquier caso, el sistema jurídico de cada estado el que delimite el margen de actuación de los particulares en las reclamaciones que puedan presentar contra el estado por no poner en marcha los mecanismos previstos en el Convenio de La Haya o aquellos que prevé el Derecho internacional público para denunciar el incumplimiento por otros estados de sus obligaciones convencionales. Volveremos sobre esto un poco más adelante.

\section{Relaciones estructurales}

9. La devolución del menor es, tal y como se ha explicado, el objetivo básico del Convenio de La Haya de 1980. Se pretende desincentivar ese traslado impidiendo que pueda suponer algún tipo de

\footnotetext{
${ }^{30}$ Un estado al que hubiera sido desplazado temporalmente el menor antes de ser trasladado al estado en el que se encuentra en el momento de iniciarse el procedimiento relativo a la sustracción, por ejemplo.

${ }^{31}$ En el siguiente epígrafe se comentará la relación existente entre las regles de competencia judicial y la resolución de los procesos de sustracción.

${ }^{32}$ El caso Boll que enfrentó a los Países Bajos y a Suecia en relación a la aplicación del Convenio de La Haya de 1902 sobre protección de menores, llegándose a la decisión de 28 de noviembre de 1958 del Tribunal Internacional de Justicia (http://www. worldlii.org/int/cases/ICJ/1958/8.html).
} 
ventaja para quien ha desplazado al menor o lo retiene en un estado diferente del de su residencia. Esta ventaja iría vinculada a la posibilidad de que las autoridades de la nueva residencia se pronunciaran sobre la cuestión de fondo; normalmente la atribución de la custodia; confiando en que esas autoridades sean más favorables a los intereses de quien promueve el desplazamiento o la retención (normalmente, uno de los progenitores) que las del estado de la residencia del niño. El supuesto típico en el que se insertaría el desplazamiento sería aquel en el que una pareja mixta (integrada por personas de nacionalidad o con residencia originariamente en estados diferentes) tiene un hijo. Una vez que surgen desavenencias en la pareja, alguno de sus integrantes intenta que sean los tribunales del estado de su nacionalidad o de donde se encuentra su origen los que se pronuncien. Dada la vinculación entre competencia en materia de responsabilidad parental y residencia del menor, se calcula que si se traslada al menor al estado cuyos tribunales pretende que se pronuncien, dicha competencia acabará siendo reconocida, siendo posible, a partir de ahí, que dicten una resolución sobre el fondo que podría paralizar el reconocimiento de las decisiones que pudieran adoptarse en otros países y también podría ser reconocida en otros estados. De esta forma, la sustracción internacional desplegaría los mismos efectos que el forum shopping ${ }^{33}$.

La devolución inmediata del menor tendría como finalidad, entre otras, evitar este pronunciamiento sobre el fondo una vez producido el desplazamiento. Dado que el criterio de competencia en materia de protección de menores es, con frecuencia, la residencia de éste ${ }^{34}$, el mantenimiento del menor en el estado al que ha sido desplazado o donde es retenido podría acabar atribuyendo competencia a los tribunales de dicho estado para pronunciarse sobre el fondo del asunto. La devolución impediría que se consolidara dicha residencia. Ahora bien, con el fin de evitar que el proceso pudiera iniciarse en el momento en el que el menor aún se encuentra en el estado que ha de proceder a su devolución, y continuara una vez producida ésta ${ }^{35}$; el Convenio de La Haya de 1980 prevé que no pueda iniciarse ningún proceso sobre el fondo hasta que no se haya decidido sobre la restitución del menor ${ }^{36}$. Se impide así que pueda especularse con la sustracción intentando que pueda tener algún efecto en relación a la determinación de la competencia en cuanto al fondo del asunto.

10. El art. 16 del Convenio de La Haya de 1980 es, por tanto, una regla que incide, al menos tangencialmente, en la regulación sobre la competencia judicial internacional en un instrumento que no regula esta materia. Tal como se ha indicado, el Convenio de La Haya es un convenio "fáctico" ${ }^{37}$ que regula la actuación de las autoridades orientada a la devolución del menor y la cooperación entre ellas. El art. 16 no supone, por tanto, una regulación de la competencia judicial internacional, sino tan solo una obligación en relación a la asunción de dicha competencia que deberá tenerse en cuenta cuando se apliquen los instrumentos que regulan directamente la competencia judicial internacional. Podría plantearse, al menos desde una perspectiva teórica, que la existencia de esta norma podría conducir a alguna contradicción con las normas reguladoras de la competencia judicial internacional; pero, como veremos, esto no es así.

En primer lugar (y de ello nos ocuparemos en el siguiente número), los diferentes instrumentos ya regulan en qué forma se han de proyectar las reglas de competencia judicial internacional sobre los casos de sustracción internacional de menores. Pero es que, además, en segundo término, la prohibición

\footnotetext{
${ }^{33}$ Cf. A. Grammaticaki-Alexion, loc. cit., p. 326.

${ }^{34}$ Vid. el art. 5 del Convenio de La Haya de 19 de octubre de 1996 relativo a la competencia, la ley aplicable, el reconocimiento, la ejecución y la cooperación en materia de responsabilidad parental y de medidas de protección de los niños (https:// www.hcch.net/es/instruments/conventions/full-text/?cid=70), el art. 8 del Reglamento 2201/2003, el art. 7 del Reglamento 2019/1111 o el art. 22 quáter d) de la Ley Orgánica del Poder Judicial.

${ }^{35}$ En aplicación del principio de perpetuatio iurisdictionis. Vid. sobre este principio y sus excepciones E.M. RODRíGUEZ GAYÁn, "Excepciones a la aplicación de la perpetuatio iurisdictionis como criterio determinante de la competencia judicial internacional", RCEA, 1993, vol. IX, pp. 107-127.

${ }^{36}$ Art. 16 del Convenio de La Haya de 1980: "Después de haber sido informados de un traslado o retención ilícitos de un menor en el sentido previsto en el artículo 3, las autoridades judiciales o administrativas a donde haya sido trasladado el menor o donde esté retenido ilícitamente, no decidirán sobre la cuestión de fondo de los derechos de custodia hasta que se haya determinado que el menor tiene que ser restituido de conformidad con lo dispuesto en el presente Convenio o hasta que se haya transcurrido un período de tiempo razonable sin que se haya presentado una demanda en aplicación del Convenio".

${ }^{37}$ Vid. supra n. núm. 16.
} 
de pronunciarse sobre el fondo de la custodia una vez advertido el traslado ilícito no ha de entenderse necesariamente como una limitación de la competencia judicial internacional, ya que, existiendo ésta, se trataría solamente de retrasar la decisión al momento en el que ya se haya decidido sobre la custodia ${ }^{38}$. Nos encontraríamos, por tanto, ante un obstáculo procesal para poder dictar una sentencia sobre el fondo, pero que no implicaría necesariamente una limitación a la competencia judicial internacional de los tribunales del estado al que se ha desplazado el menor. De hecho, el art. 16 del Convenio de La Haya de 1980 debe operar incluso en aquellos casos en los que no hay duda sobre la competencia judicial internacional de los tribunales del estado al que se ha desplazado o donde se encuentra retenido el menor ${ }^{39}$

11. La asunción de competencia en cuanto al fondo del asunto cuando todavía no se ha decidido sobre el retorno del menor es, por tanto, una infracción directa del Convenio de la Haya de 1980; pero puede tener consecuencias también más allá de este instrumento. Dado que, como hemos visto, el criterio habitual de competencia en materia de responsabilidad parental es la residencia, si los tribunales del estado al que ha sido desplazado el menor asumen competencia en relación al fondo del asunto, pese a que no pueda considerarse al menor como residente en dicho estado; se estaría vulnerando también la normativa sobre competencia judicial internacional contenida en los instrumentos que regulan esta materia.

Ciertamente, podría plantearse la duda de si el hecho de que el menor se encuentre en el estado al que ha sido desplazado o donde ha sido retenido ha de bastar para considerar que su residencia se haya en dicho estado ${ }^{40}$; ahora bien, en algunos instrumentos ya se ha tenido en cuenta este problema y se ha indicado expresamente que en los casos de sustracción internacional de menores la competencia sobre el fondo del asunto se mantiene en los tribunales del estado donde se encontraba la residencia del menor antes del desplazamiento ilícito ${ }^{41}$. De esta forma, la asunción de competencia sin que se haya resuelto sobre la cuestión de la sustracción podría suponer también desconocer la regulación en materia de competencia judicial internacional. Incluso aunque no fuera así, el pronunciamiento supondría la vulneración del art. 16 del Convenio de La Haya ${ }^{42}$

Llamamos la atención sobre las relaciones entre la determinación de la competencia judicial internacional y la sustracción de menores porque en el caso que nos servía para introducir el problema se ha producido la situación que se describía en el número anterior: se decidió sobre el fondo del asunto (la custodia del niño) antes de resolver sobre su retorno a España. Es más, de acuerdo con las informaciones de las que disponemos, se hizo expreso que se suspendía el proceso de restitución en tanto en cuanto no se resolviera sobre el fondo, lo que supone realizar justamente lo contrario a lo obligado de acuerdo

${ }^{38}$ El art. 16 del Convenio de La Haya no supondría, por ejemplo, la terminación de los procedimientos abiertos sobre la custodia del menor en el estado al que ha sido desplazado, sino su suspensión, vid. G. CARELLA, "La Convenzione dell'Aja del 1980 sugle aspetti civile della sotrazione internazionale di minori”, Riv. dir. int. pr. proc., 1994, año XCIII, núm. 4, pp. 777-794, p. 788. Vid. también sobre esta perspectiva R. Arenas García, Crisis matrimoniales internacionales. Nulidad matrimonial, separación y divorcio en el nuevo Derecho internacional privado español, Santiago de Compostela, Universidade de Santiago de Compostela, 2004, pp. 96-105; P. JimÉNez BlanCO, op. cit., pp. 52-53.

${ }^{39}$ Porque esa competencia se derive, por ejemplo, de la nacionalidad del menor, tal como prevé, por ejemplo, el art. 4 del Convenio de La Haya de 1961 (Convenio de 5 de octubre de 1961 sobre Competencia de Autoridades y Ley Aplicable en Materia de Protección de Menores, https://www.hcch.net/es/instruments/conventions/full-text/?cid=39). Existe, sin embargo, jurisprudencia contradictoria sobre esta cuestión en diversos estados, vid. las referencias contenidas en P. JIMÉNEZ BLANCO, op. cit., pp. 53-54, n. núm. 71.

${ }^{40}$ Vid. P. JimÉnez Blanco, op. cit., pp. 28-30.

${ }^{41}$ Vid. el art. 7 del Convenio de La Haya de 1996 sobre protección de los niños, el art. 10 del Reglamento 2201/2003 y el art. 9 del Reglamento 2019/1111. Sobre la necesidad de extender dicho mantenimiento de la competencia también en los casos en los que el desplazamiento del menor se produzca a un estado no vinculado por estos instrumentos vid. P. JIMÉNEZ BLANCO, op. cit., pp. 31-32.

${ }^{42}$ En España es necesario hacer referencia a la sentencia de la AP de Almería de 27 de octubre de 1993 (REDI, 1994, vol. XLVI, núm. 1, pp. 341-342, "Nota” de S. Álvarez GonZÁlez, ibid, pp. 342-345) que pese a ordenar la restitución de los menores entró en el fondo del asunto. Esta sentencia fue objeto de recurso de casación ante el TS, quien en sentencia de 22 de junio de 1998 declaró que la interpretación correcta del art. 16 del Convenio de La Haya es la de que los órganos jurisdiccionales del estado al que se ha desplazado el menor no podrán pronunciarse sobre el fondo del asunto en tanto no se haya determinado que no procede la restitución del menor. Vid. el comentario a esta sentencia de J.M. EsPinAr Vicente ("Comentario a la Sent. 604/1998 de la Sala $1^{\text {a }}$ del TS. Recurso en interés de ley. Sustracción internacional de menores. Interpretación del articulo 16 del Convenio de La Haya de 1980”, AC, 1999, núm. 2, pp. 31-47). 
con lo previsto en el art. 16 del Convenio de La Haya. Ahora tendremos que examinar qué mecanismos existen para poner remedio a situaciones como ésta.

\section{Convenio de La Haya de 1980}

\section{El seguimiento de la aplicación del Convenio}

12. A salvo de la posibilidad de acudir al TIJ en caso de que un estado vinculado por el Convenio considere que otro estado no está cumpliendo las obligaciones que se derivan de él ${ }^{43}$, no existe un órgano supranacional que determine de manera definitiva si se ha producido un incumplimiento del Convenio de La Haya. Esta ausencia, que es propia de todos los instrumentos convencionales, no puede ser obviada cuando se analizan los posibles incumplimientos del instrumento. Es claro que la autoridad que puede haber incurrido en dicho incumplimiento no creerá -en la mayoría de los casosque ha obrado al margen de los previsto en el instrumento internacional; o si es consciente de que su comportamiento no se ajusta a lo previsto en el Convenio, pretenderá que su actuación está cubierta por la necesidad de atender a una obligación jurídica que resulta de otra fuente normativa (una ley interna, su Constitución, otro instrumento internacional...). De esta forma, no nos encontraremos nunca ante un incumplimiento "objetivo" del Convenio, sino ante una divergencia de opiniones sobre la corrección en la aplicación del instrumento.

De hecho, incluso si existiera un pronunciamiento del TIJ en la materia no estaríamos más que ante otra opinión subjetiva (en este caso, del TIJ); pero con la diferencia de que en este caso esa opinión subjetiva sería dotada de relevancia definitiva; que es lo que caracteriza a la función jurisdiccional ${ }^{44}$. Fuera, sin embargo, de esta posibilidad de recurso al TIJ, las discrepancias que puedan existir en relación a la aplicación del Convenio no se podrán traducir en una declaración vinculante de incumplimiento; lo que no quiere decir que no existan vías para denunciar la falta de adecuación de la actuación de las distintas administraciones implicadas a las exigencias derivadas de la Convención.

13. La Conferencia de La Haya de DIPr es un actor decisivo en relación a la verificación del grado de cumplimiento del instrumento; ya que habilita mecanismos que permiten hacer un seguimiento de la aplicación del Convenio. Estos mecanismos se han traducido en la celebración de varias comisiones especiales en relación a la aplicación del Convenio, pudiendo aprovecharse también las reuniones periódicas de la Conferencia de La Haya para poner sobre la mesa los problemas detectados en la aplicación del instrumento ${ }^{45}$. De hecho, esta mecánica de seguimiento del funcionamiento de los convenios elaborados ha llevado a que se escriba que la Conferencia de La Haya ha pasado de ser una "fábrica de Convenios" a una "niñera de Convenios" ${ }^{4}$. La enorme relevancia práctica del Convenio sobre sustracción de menores justifica que haya una atención continuada sobre la forma en que es aplicado en los diferentes estados y que se ha traducido en la celebración de siete reuniones de la Comisión especial para el seguimiento de la aplicación del Convenio ${ }^{47}$. Además, se han elaborado otros documentos en el marco de la Conferencia, como guías de buenas prácticas en los diferentes aspectos relevantes para la aplicación del Convenio (co-

\footnotetext{
${ }^{43}$ Y que comentábamos supra en el núm. 8 y sobre la que tendremos que volver en el epígrafe III.3.

${ }^{44}$ Y aquí, de nuevo, es indispensable la cita de la monografía de J.L. ReQUejo PAgÉs que ya ha sido mencionada en la n. núm. 6.

${ }^{45}$ Vid. por ejemplo, A. Borrás RodríGuez, “Comisión especial de octubre de 1989...”, loc. cit., p. 289, donde explica las quejas que se le formularon, como representante española, los delegados de otros países en relación a la aplicación del Convenio de La Haya en nuestro país.

${ }^{46}$ Cf. A. Borrás Rodríguez, "La Conferencia de La Haya de Derecho internacional privado: pasado, presente y futuro", REDI, 2019, vol. 71, núm. 2, pp. 23-26, p. 26.

${ }^{47} \mathrm{Vid}$. supra n. núm. 4. Los documentos relativos a estas reuniones están accesibles aquí: https://www.hcch.net/en/instruments/conventions/publications $1 /$ ?did= $57 \& \mathrm{cid}=24$. Los documentos no se limitan a las conclusiones de la Comisión, sino que incluyen los documentos preliminares que incluyen estudios e información sobre la aplicación del Convenio y las dificultades que se encuentran en dicha aplicación. Las reuniones quinta, sexta y séptima trataron conjuntamente la aplicación de los Convenios de La Haya de 1980 sobre sustracción internacional de menores y de 1996 sobre protección de menores.
} 
municación entre autoridades judiciales o mediación, por ejemplo) o cuestionarios dirigidos a los estados en relación a las dificultades que se plantean en relación al instrumento ${ }^{48}$.

14. Los mecanismos que se acaban de describir se enmarcarían en lo que se conoce como "soft law". Se trata de guías o recomendaciones, no de obligaciones. Esto, sin embargo, no les priva de eficacia; lo que sucede es que implica una metodología diferente de la que apreciamos cuando un tribunal ha de decidir sobre una pretensión concreta declarando un incumplimiento, estableciendo una obligación y reconociendo un derecho. Nada de esto opera aquí. Así, se evita hablar de incumplimientos y se prefiere utilizar el término "problema" tencia de interpretaciones divergentes en diferentes estados de los mismos conceptos del Convenio no es presentada mediante la dicotomía entre interpretaciones correctas e incorrectas; sino que la divergencia en sí se plantea como una circunstancia que ha de superarse a través de las herramientas existentes o mediante otras que puedan crearse $\mathrm{e}^{50}$.

Esta aproximación es, probablemente, la única posible ante la ausencia de instrumentos efectivos que puedan determinar cuál es la interpretación correcta de los términos del Convenio, concretar las obligaciones que se derivan del instrumento de manera imperativa y forzar a su cumplimiento en el caso de que este no se produzca de manera voluntaria. Ante la ausencia de esta posibilidad; el conocimiento de la situación real en la aplicación del Convenio y su denuncia pueden ser mecanismos eficientes. Si se siguen las crónicas de A. Borrás ${ }^{51}$ sobre las Comisiones Especiales sobre el funcionamiento del Convenio de La Haya de 1980 queda claro: en la reunión de 1989 se puso de manifiesto que España no estaba procediendo a la devolución de los menores con la celeridad y en las condiciones fijadas por el Convenio ${ }^{52}$; lo que condujo a que España llevara a cabo diversas actuaciones que condujeron a que en la siguiente reunión de la Comisión Especial, la celebrada en el año $1993^{53}$ se hiciera explícita la evolución positiva de la práctica española en la aplicación del Convenio ${ }^{54}$.

Se trata, sin embargo, de medidas que ninguna influencia pueden tener en relación a los casos concretos ya resueltos. Las vulneraciones que puedan sufrir las personas como consecuencia del incumplimiento del Convenio no se verán satisfechas por el seguimiento que hagan el resto de estados o la Conferencia de La Haya de DIPr de las dificultades o problemas que se identifican en la aplicación del instrumento. Para esto deberemos recurrir a otros mecanismos.

\section{El recurso al Tribunal de Estrasburgo}

15. La aplicación del Convenio de La Haya de 1980 no es indiferente para el Convenio Europeo de Derechos Humanos (CEDH). Son varias las resoluciones del TEDH que se ocupan de supuestos de

\footnotetext{
${ }^{48}$ Todos estos documentos están accesibles en la página web de la Conferencia de La Haya de Derecho internacional privado, https://www.hcch.net/en/instruments/conventions/specialised-sections/child-abduction.

${ }^{49} \mathrm{Vid}$., por ejemplo, la conclusión núm. 3 adoptada en la séptima reunión de la Comisión Especial sobre la aplicación de los Convenios de 1980 y de 1996 del año 2017 (https://assets.hcch.net/docs/edce6628-3a76-4be8-a092-437837a49bef.pdf): "The Special Commission acknowledges that globally is still a severe problem of delays that affect the efficient operation of the Convention".

${ }^{50}$ Vid. la conclusión núm. 19 de la séptima reunión de la Comisión Especial a la que nos referíamos en la n. anterior: “The Special Commission notes significant variations among Contracting States as to their interpretation of the scope of Article 21, as well as on the relationship betwenn Access/contact under the 1980 Convention and under the 1996 Convention. In the interest of securing protection for access/contact rights under both Conventions, the Special Commission invites the Permanent Bureau to: i) identify existing variations and discrepancies; ii) assess to what extent they could be addressed and clarified with existing HCCH tools; and, iii) in due course report to the Council on General Affairs and Policy, for a decision on the kind of work, if any, that should be developed in advance of the next Special Commission".

${ }^{51}$ Vid. supra n. núm. 4.

${ }^{52}$ Cf. A. Borrás RodríGUEz, loc. cit. supra n. núm. 45, p. 289.

${ }^{53}$ Aquí puede leerse el informe relativo a esa reunión: https://www.hcch.net/upload/abdrpt93e.pdf.

${ }^{54}$ Vid. p. 3. Vid. también A. Borrás Rodríguez, "Conferencia de La Haya de Derecho internacional privado: Comisión especial sobre la aplicación del Convenio de 1980 sobre sustracción internacional de menores (La Haya, 18-21 de enero de 1993)", REDI, 1993, vol. XLV, núm. 2, pp. 645-647, pp. 646-647.
} 
sustracción internacional de menores y de cómo la aplicación o inaplicación del Convenio de La Haya ha incidido en los derechos amparados por el $\mathrm{CEDH}^{55}$. De esta manera, el Tribunal de Estrasburgo se ha convertido en una institución relevante para la aplicación del Convenio de 1980 en aquellos estados parte de éste último que también están vinculados por el primero. Ahora bien, la función del TEDH no es determinar si el Convenio de La Haya se ha aplicado correctamente, por lo que las valoraciones que realice este Tribunal han de insertarse en el control que hace del cumplimiento del CEDH.

La conexión entre el CEDH y el Convenio de la Haya se produce, fundamentalmente, a través del derecho a la vida personal y familiar. La vida del menor se ve perturbada por la sustracción, que además supone normalmente la ruptura de la vida familiar que el menor mantenía con el progenitor $(\mathrm{u}$ otra persona con la que conviviera) con el que residía antes de la sustracción o la retención. Dado que la sustracción, normalmente, se realiza sin intervención de las autoridades públicas, el desplazamiento o la retención en sí no pueden ser objeto de fiscalización ante el TEDH, que es competente para determinar si son los estados, incluyendo aquí todas las administraciones que lo integran, quienes han vulnerado los derechos recogidos en el CEDH. Ahora bien, la actuación o la no actuación, tanto del estado de origen del menor como aquel al que ha sido desplazado (siempre que se trate de estados vinculados por el CEDH) sí puede ser objeto de enjuiciamiento por el Tribunal de Estrasburgo, quien determinará si se ha producido una injerencia no justificada en la vida privada y familiar (obligación negativa) como un incumplimiento de la obligación positiva de adoptar las medidas necesarias para restablecer la vida familiar que había sido perturbada. Nos ocuparemos de ello a continuación.

16. En lo que se refiere a la obligación positiva, ésta se concretará en la necesidad de que las autoridades adopten todas las medidas necesarias para conseguir la devolución del menor en caso de que esto sea lo que corresponde hacer de acuerdo con el interés superior del menor. Así se estableció en la STEDH de 29 de abril de $2003^{56}$, en la que se trataba de determinar si las autoridades españolas habían hecho los esfuerzos necesarios para conseguir el retorno desde Estados Unidos de un menor que había sido desplazado desde España por uno de sus progenitores. El otro progenitor (la madre) había denunciado el caso ante los tribunales españoles por la vía penal, y pese a que era evidente que el menor había sido desplazado a Estados Unidos, que es estado parte del Convenio de La Haya de 1980, las autoridades españolas no utilizaron los mecanismos previstos en el Convenio. El TEDH recuerda que no era preciso que el Convenio fuera alegado por el progenitor interesado, pudiendo las autoridades actuar de oficio ${ }^{57}$. De hecho, cabría plantearse que en caso de que la normativa aplicable no permitiera esta actuación de oficio, podría existir incumplimiento del estado en tanto en cuanto le corresponde a éste dotarse de los medios necesarios para garantizar la efectividad de los derechos recogidos en el CEDH y, en el caso que nos ocupa, específicamente del derecho a la vida personal y familiar recogido en el art. 8 del mencionado Convenio ${ }^{58}$.

Así pues, en los casos en los que se produzca el desplazamiento o la retención ilícitos y este desplazamiento suponga una perturbación de la vida personal y familiar del menor o de las personas que con él se relacionan (normalmente sus otros progenitores, pero sin que se excluya a otros familiares ${ }^{59}$ ), la no utilización de los mecanismos que ofrece el Convenio de La Haya puede ser considerado como una vulneración de la obligación positiva del estado de poner los medios necesarios para restablecer la vida familiar. Hemos visto decisiones en las que se ha declarado que la no actuación de las autoridades del estado donde se encontraba inicialmente la residencia habitual del menor suponían una vulneración del

\footnotetext{
${ }^{55}$ Vid. J.C. Fernández Rozas/S. SÁnchez Lorenzo, op. cit., pp. 430-431.

56 STEDH de 29 de abril de 2003, Iglesias Gil and A.U.I. v. España, solicitud n ${ }^{\circ}$ 56673/00,

${ }^{57}$ Vid. en particular los núms. 57 a 59 de la sentencia. Reproduzco el núm. 59: "Once the Spanish authorities had established that the child had been wrongfully removed, the Court considers that the national authorities concerned should have taken appropriate measures as set out in the relevant provisions of the Hague Convention to secure his return to its mother. The authorities did not take any of the measures prescribed in the Hague Convention to facilitate the enforcement of the court orders in favour of the first applicant and her child".

58 Vid. los núms. 107 y 108 de la STEDH de 25 de enero de 2000, Ignaccolo-Zenide v. Rumanía, solicitud nº 31679/96).

${ }^{59}$ Vid. M. Presno Linera, "El Derecho Europeo de Familia", Cuadernos Aranzadi del Tribunal Constitucional, núm. 22, 2008, pp. 17-18 y referencias ahí contenidas sobre la extensión de la protección de la vida familiar a personas que no son los progenitores y sus hijos.
} 
CEDH; pero, por la misma razón, el incumplimiento de estas obligaciones por parte de las autoridades del estado al que se ha desplazado al menor o donde se le ha retenido debería suponer igualmente un incumplimiento de las obligaciones que se derivan del CEDH.

17. Si de las obligaciones positivas pasamos a las negativas, comprobamos que el estado estará obligado a respetar la vida personal y familiar y no injerir en ella sin causa justificada. En este caso la relación entre el Convenio de la Haya y el CEDH es, quizás, más problemática, puesto que en los casos en los que se ha planteado la forma en que incide el segundo sobre el primero lo que se ha examinado es si el retorno decidido por las autoridades del estado en el que se encuentra el menor sustraído es compatible con las exigencias de respeto a la vida familiar teniendo en cuenta el interés superior del menor. Ya habíamos adelantado que esta tensión entre obligación de retorno y verificación de lo más adecuado en cada caso para el menor suponía examinar la forma en que se aplicaban las excepciones a la devolución que recoge el Convenio de La Haya de $1980^{60}$, de tal forma que se haga compatible la aplicación de este Convenio y el respeto a las exigencias que se derivan del CEDH. Lo que en ocasiones puede no ser sencillo.

Desde esta perspectiva, la de las obligaciones negativas, el TEDH no reforzará la aplicación del Convenio de La Haya de 1980, sino que, en su caso, entenderá que no se produce infracción del CEDH cuando se adopte una decisión de retorno en el marco del Convenio de La Haya por entender que esa decisión de retorno, pese a que afecte a la vida personal o familiar del menor tal como se estaba desarrollando en el estado al que había sido desplazado o donde había sido retenido, se ajusta a la ley y responde a los fines que recoge el art. 8.2 del $\mathrm{CEDH}^{61}$. Pueden existir supuestos, sin embargo, en los que entienda que esa devolución no responde a ese interés o que se ha producido sin respetar las necesarias garantías del procedimiento; con lo que en este caso desautorizará la aplicación del Convenio de $1980^{62}$. A partir de aquí, deberá determinarse si nos encontramos ante una mala aplicación del Convenio de La Haya, que a su vez ha llevado a una quiebra del CEDH, o si, por el contrario, es el propio tenor del Convenio el que no se ajusta a las exigencias del sistema europeo de protección de Derechos Fundamentales. Lógicamente, el TEDH no es quien ha de pronunciarse sobre este extremo de una manera definitiva, por lo que lo que en realidad se abre es un diálogo entre el Tribunal de Estrasburgo y los tribunales nacionales al que ha de estar atenta la Conferencia de La Haya de DIPr.

18. Da cuenta de este diálogo la Conclusión núm. 17 de la Séptima reunión de la Comisión especial sobre la aplicación práctica de los Convenios de La Haya de 1980 y de 1996 del 10 al 17 de octubre de $2017^{63}$, en la que se toma nota de la jurisprudencia del Tribunal de Estrasburgo en relación al Convenio de La Haya, en concreto, la decisión $X$. v. Letonia, que había sido dictada después de la sexta reunión de la Comisión especial ${ }^{64} \mathrm{y}$ destaca la explícita referencia del TEDH a la necesidad de considerar el Convenio de La Haya en la resolución de los casos de sustracción internacional de menores ${ }^{65}$. El Tribunal de Estrasburgo defiende una aplicación armoniosa del Convenio de La Haya y del Convenio de 1980 a partir de la consideración del interés superior del niño como eje tanto del Derecho internacional como del Convenio de La Haya ${ }^{66}$. De esta forma, sería posible hacer compatibles las exigencias derivadas del Convenio y las que se derivan del CEDH.

${ }^{60}$ Vid. supra núm. 6 y especialmente las STEDH de 6 de julio de 2010, Neulinger y Shuruk v. Suiza (solicitud n ${ }^{\circ} 41615 / 07$ ) y de 26 de noviembre de 2013, $X$ v. Letonia (solicitud nº 27853/09).

${ }^{61}$ Vid. núm. 54 de la sentencia $X$. v. Letonia.

${ }^{62}$ Vid. $\mathrm{M}^{\mathrm{a}} \mathrm{V}$. Cuartero Rubio, loc cit., esp. epígrafe III.

${ }^{63}$ Vid. supra n. núm. 49.

${ }^{64}$ Que tuvo lugar en el año 2011. Aquí se puede acceder a los documentos de esa reunión: https://www.hcch.net/en/publications-and-studies/details4/?pid=6224\&dtid $=57$.

${ }^{65} \mathrm{Vid}$. núms. 92 y ss. de la sentencia X. v. Letonia.

${ }^{66}$ Vid. núm. 94 de la sentencia ("This approach involves a combined and harmonious application of the international instruments, and in particular in the instant case of the Convention and the Hague Convention, regard being had to its purpose and its impact on the protection of the rights of the children and parents"), núm. 96 ("The Court reiterates that there is a broad consensus -including in international law- in suport of the idea that in all decisions concerning children, their best interests must be paramount") y núm 97 ("The same philosophy is inherent in the Hague Convention, which associates this interest 
El resultado de lo anterior es que será necesario interpretar las excepciones a la devolución de tal manera que cubran todos aquellos casos en los que dicha devolución no responda al interés superior del menor. Si se actúa de esta manera, resultará que aquellos casos en los que se aplique incorrectamente el Convenio de La Haya, forzando el retorno en un caso en el que no debería procederse al mismo, serán susceptibles de recurso ante el Tribunal de Estrasburgo, quien debería apreciar la vulneración del art. 8 del CEDH que resultaría de dicha devolución.

19. De acuerdo con lo que se acaba de ver, el recurso al Tribunal de Estrasburgo se convertiría en un mecanismo especialmente útil para denunciar las vulneraciones del Convenio de La Haya de 1980. En los supuestos de sustracción internacional de menores es habitual que haya dos situaciones familiares en conflicto; la que se daba antes de la sustracción y la que se crea como consecuencia de esta. Sobre la base de la primera se podrá exigir la aplicación de los mecanismos del Convenio de La Haya para la devolución del menor. Sobre la de la segunda se podrá denunciar la orden de devolución. En cualquiera de los dos casos habrá una situación familiar perjudicada, siendo aquí imprescindible el recurso al Convenio de La Haya, que recoge -como hemos visto- el principio de retorno del menor; aunque excepcionándolo para aquellos casos en los que dicho retorno no responda al interés superior del menor.

Interpretado de esta forma, la coherencia entre el CEDH y el Convenio de La Haya de 1980 puede mantenerse; pero para ello será necesario un diálogo constante entre el Tribunal de Estrasburgo, la Conferencia de La Haya de DIPr y las autoridades nacionales.

Es necesario también indicar que en los casos en los que se aprecie una vulneración del CEDH el Tribunal puede establecer una indemnización en favor de la persona perjudicada (art. 41). La única vía posible de resarcimiento en el caso de incumplimiento por parte de un Estado de las obligaciones derivadas del Convenio de La Haya de 1980 sobre sustracción internacional de menores.

\section{Otras medidas}

20. En los supuestos en los que se agotan los recursos internos y se constata que se ha producido el incumplimiento del Convenio de La Haya (siempre desde la perspectiva subjetiva de la persona afectada, por supuesto), cabe, como acabamos de ver, recurrir al Tribunal de Estrasburgo; para los casos en los que la vulneración alegada ha sido causada por un estado vinculado por el CEDH. Ahora bien, al margen de esta posibilidad ¿qué otras vías le quedan a quien cree que ha sido perjudicado por esta inaplicación o equivocada aplicación del instrumento?

Si asumimos que el incumplimiento se produce en el estado al que el menor ha sido desplazado, se podría acudir a las autoridades del estado de la residencia del menor con anterioridad a la sustracción a fin de pedir que tales autoridades ejerciten las facultades que les atribuye el Convenio para instar la devolución del menor, y que ya hemos examinado en el epígrafe II.2. En caso de que las autoridades (la Autoridad Central) no acojan esta petición, aún sería posible, al menos en algunos sistemas jurídicos, recurrir a los tribunales para forzar esta actuación de la administración. Así, en el caso del Derecho español, el art. 29 de la Ley de la Jurisdicción Contencioso-Administrativa ${ }^{67}$, prevé la posibilidad de recurso contra la inactividad de la administración cuando en virtud de una disposición general que no precise actos de aplicación o en virtud de un acto, contrato o convenio administrativo, esté obligada a realizar una prestación concreta en favor de una o varias personas determinadas. Transcurridos tres meses tras la reclamación infructuosa a la administración cabe plantear el recurso a los tribunales. El Convenio de La Haya de 1980 podría ser considerado como una norma general que, sin precisar actos de aplicación, genera unas determinadas obligaciones para la administración que redundan en derechos para los interesados; en este caso las personas afectadas por el traslado o retención ilícitos del menor.

with restoration of the status quo by means of a decision ordering the child's immediate return to his or her country of habitual residence in the event of unlawful abduction, while taking account of the fact that non-return may sometimes prove justifies for objective reasons that correspond to the child's interests, thus explaining the existence of exceptions").

${ }^{67}$ Ley 29/1988, de 13 de julio, reguladora de la Jurisdicción Contencioso-administrativa, BOE, 14-VII-1998. 
El requerimiento puede darse también en relación a la necesaria cooperación que las autoridades del estado de origen del menor han de prestar a las autoridades del estado en el que se encuentra el menor $^{68}$. La inactividad de las autoridades en esta cooperación también podría ser impugnado ante los tribunales, al menos en España.

21. En caso de el procedimiento de sustracción haya concluido de manera definitiva en el estado al que ha sido desplazado o en el que ha sido retenido el menor, podríamos encontrarnos ante un caso de responsabilidad internacional del estado derivada del incumplimiento de sus obligaciones internacionales. Otros estados parte del Convenio podrían exigir la responsabilidad que se derivara de ese incumplimiento, incluido aquí el estado de la residencia originaria del menor; pero en este caso, la decisión del estado para el inicio del procedimiento internacional no podría ser instado por las personas interesadas con posibilidad de recurrir a los tribunales en caso de negativa de la administración. El art. 29 de la Ley de la jurisdicción contencioso-administrativa que acabamos de mencionar solamente prevé la posibilidad de instar judicialmente la actuación de la administración cuando la persona que actúa tiene algún derecho frente a esta administración, y en este caso no lo hay. El ejercicio de la responsabilidad internacional del estado por el incumplimiento del Convenio no se trasladaría de ninguna forma a la persona que hubiera podido ser perjudicada por dicho incumplimiento, por lo que la decisión sobre actuar o no le corresponde únicamente al estado, sin que pueda aquí verse constreñido por las peticiones de los particulares que hubieran sido afectados por el incumplimiento del estado al que había sido desplazado el menor.

Las actuaciones del estado que, de acuerdo con el Derecho internacional, podrían llevarse a cabo para obtener la declaración de la responsabilidad del estado infractor pueden incluir actuaciones ante el TIJ, la búsqueda de un arreglo por medio de un arbitraje y otros medios como la negociación o la mediación ${ }^{69}$. Todas ellas, sin embargo, y como se acaba de indicar, dependerían de la voluntad del estado y, como se ha adelantado, no es frecuente que el incumplimiento de las normas de DIPr provoquen conflictos diplomáticos.

22. El estado también puede utilizar los mecanismos de la protección diplomática en relación a las infracciones del Convenio de La Haya ${ }^{70}$. Ahora bien, hay que tener en cuenta ciertas limitaciones. En primer lugar, que la protección solamente puede ejercerse en favor de los propios nacionales ${ }^{71}$, por lo que en casos en los que quienes estén afectados sean personas que no son nacionales del país de la residencia del menor con anterioridad a la sustracción no podrán verse beneficiados por la protección diplomática ejercida por este país. En el caso con el que se iniciaba esta exposición era eso justamente lo que sucedía: ni el menor sustraído ni su madre eran nacionales españoles, por lo que no existía posibilidad alguna que el estado cuyas autoridades centrales reclamaban la devolución del menor pudieran ejercer la protección diplomática respecto a él.

Además, el particular no tiene un derecho subjetivo al ejercicio de la protección diplomática, por lo que no dispondrá de mecanismos para exigirla. Será decisión discrecional del estado poner en marcha los mecanismos de la protección diplomática. La razón de ello es que el derecho que se ejerce es el propio del estado, no el de los individuos que pudieran verse afectados por el incumplimiento. Esto es, el estado no actúa como representante de los sujetos perjudicados, sino que lo que exige es el cumplimiento de las normativas internacionales en las que el estado es parte y que vinculan a otros estados ${ }^{72}$. Ahora bien, en el caso de España, si el estado no ejerce la protección diplomática y de ello se deriva un perjuicio para el particular, surge un derecho de indemnización que sí puede ser ejercitado ante los tribunales ${ }^{73}$.

\footnotetext{
${ }^{68} \mathrm{Vid}$., por ejemplo, el párrafo tercero del art. 13 del Convenio.

${ }^{69}$ Vid. sobre esto J.D. González Campos/L.I. Sánchez Rodríguez/P. Andrés Sáenz de Santa María, Curso de Derecho internacional público, Madrid, Civitas, $6^{\text {a }}$ ed. 1998, pp. 819 y ss.

${ }^{70}$ Sobre la protección diplomática vid. J.D. GonzÁlez Campos/L.I. SÁnchez Rodríguez/P. Andrés SÁenz de Santa María, op. cit., pp. 375 y ss.

${ }^{71}$ Ibidem, p. 376.

${ }^{72}$ Ibidem.

${ }^{73}$ Ibidem, p. 384.
} 
23. Vemos, por tanto, que el particular afectado por el incumplimiento del Convenio de La Haya de 1980 carece prácticamente de vías efectivas para denunciar dicho incumplimiento más allá del recurso al Tribunal de Estrasburgo en los términos que habíamos visto en el epígrafe anterior. No obstante, hay que señalar que en algunos países podrá instarse judicialmente la actuación de las autoridades para que requieran a las del estado en el que se encuentra el menor la aplicación de los mecanismos previstos en el Convenio sobre sustracción internacional de menores.

Los recursos generales de Derecho internacional público para exigir el cumplimiento de las obligaciones internacionales o la declaración de la responsabilidad que se deriva del incumplimiento están abiertos tan solo al estado como tal, sin que el particular tenga un derecho subjetivo a su utilización; aunque no puede descartarse que en aquellos casos en que quepa el ejercicio de la protección diplomática, la negativa a proteger al propio nacional pueda conducir a la necesidad de indemnizar los daños padecidos como consecuencia de la inaplicación del Convenio de 1980 por parte de las autoridades del estado en el que se encuentra el menor.

\section{Reglamentos de la UE}

\section{El papel de la Comisión Europea, otras instituciones y los estados}

24. Si del Convenio de La Haya pasamos a los Reglamentos europeos, la situación es completamente diferente. Al formar parte del ordenamiento de la UE, el respeto a los mismos se ve garantizado por los mismos mecanismos que el resto del Derecho europeo. Aquí el papel del Tribunal de Luxemburgo será determinante; pero antes de entrar en ello examinaremos el papel de la Comisión Europea y otras instituciones. En particular, será muy relevante el papel de la Comisión como institución encargada de velar por la aplicación de los Tratados y de las medidas adoptadas por las instituciones y de supervisar la aplicación del Derecho de la Unión (art. 17.1 del TUE); pero, como veremos, eso no excluye que otras instituciones o los estados miembros tengan un papel en la garantía del cumplimiento de los Reglamentos europeos.

Los mecanismos existentes para garantizar el cumplimiento de la normativa europea descansan, en última instancia, en la posibilidad de obtener una declaración de infracción dictada por el Tribunal de Luxemburgo; pero precisamente la existencia de esta posibilidad habilita mecanismos más flexibles que, en la práctica, pueden resultar de gran ayuda no solamente en la garantía del cumplimiento del Derecho de la UE, sino también para la resolución de las dificultades interpretativas que inevitablemente se plantearán.

25. El elemento nuclear en el papel de la Comisión como garante del cumplimiento del Derecho de la UE es la posibilidad que le ofrece el art. 258 del TFUE, y que la habilita para emitir un dictamen motivado sobre el incumplimiento, por parte de un Estado, de las obligaciones que le incumben en virtud de los Tratados. Previamente habrá de darse oportunidad al estado para presentar sus observaciones; pero una vez emitido el dictamen, el estado deberá atenerse a él. En caso de no hacerlo queda abierta la vía de recurso al Tribunal de Luxemburgo ${ }^{74}$. En el epígrafe 2 nos ocuparemos de este recurso ante el Tribunal de Justicia que, como veremos, también está abierto a los estados. Estos, sin embargo, antes de acudir al Tribunal de Luxemburgo habrán de presentar el caso ante la Comisión ${ }^{75}$, quien deberá emitir un dictamen motivado tras dar a los estados la posibilidad de presentar sus observaciones (art. 259.3 del TFUE).

De esta forma, a diferencia de lo que sucede en el caso del Convenio de La Haya de 1980, sí que existe una institución que tiene atribuida la capacidad de realizar una interpretación "correcta" de los instrumentos, aunque supeditada al criterio último del Tribunal de Luxemburgo. Tal y como ya se

${ }^{74}$ Art. 258.2 del TFUE: "Si el Estado de que se trate no se atuviere a este dictamen en el plazo determinado por la Comisión, ésta podrá recurrir al Tribunal de Justicia de la Unión Europea".

${ }^{75}$ Art. 259.2 del TFUE: "Antes de que un Estado miembro interponga, contra otro Estado miembro, un recurso fundado en un supuesto incumplimiento de las obligaciones que le incumben en virtud de los Tratados, deberá someter el asunto a la Comisión”. 
explicaba un poco más arriba ${ }^{76}$, esta corrección deriva, precisamente, de que se atribuye esa función a la institución, pero no de que necesariamente sus argumentos o criterios sean superiores a los de cualquier otro; pero hecha esta salvedad, lo cierto es que este papel de la Comisión permitirá, al menos, obtener una declaración sobre el incumplimiento de los Reglamentos europeos en caso de que este incumplimiento se produzca.

26. La declaración del incumplimiento por parte de un Estado no es, sin embargo, frecuente (afortunadamente), pero la posibilidad de dicha declaración es un potente incentivo para que cada estado intente poner todos los medios para la correcta aplicación de los instrumentos de la UE. De esta forma, y tal como habíamos comentado en relación al Convenio de La Haya de 1980, en vez de hablar de "incumplimientos" se habla de "problemas" o "dificultades", lo que implica un enfoque complementario y que puede resultar útil. En el caso de la cooperación judicial civil, en el que se enmarcan los Reglamentos que se ocupan de la sustracción internacional de menores ${ }^{77}$, existe, además, una previsión específica (art. 70 del TFUE), que habilita al Consejo para adoptar, a propuesta de la Comisión, medidas en relación a la cooperación entre los Estados miembros y la Comisión para efectuar una evaluación de la aplicación por las autoridades de los estados miembros de las políticas de la Unión. Además, deberá informarse sobre los resultados de la evaluación al Parlamento Europeo y a los Parlamentos nacionales. De esta forma, se pretende contar con herramientas que permitan la cooperación entre las autoridades de distintos estados y las autoridades de la UE, así como afrontar las dificultades en la aplicación de los instrumentos y sus problemas de interpretación.

Como resultado de lo anterior, se cuenta con la Red Judicial Europea en materia civil y mercantil, creada en el año $2001^{78}$ que, entre otros fines, tiene el buen desarrollo de los procedimientos que tengan una incidencia transfronteriza y la agilización de las solicitudes de cooperación judicial entre los estados miembros, así como la aplicación efectiva y concreta de actos comunitarios o convenios en vigor entre dos o más estados miembros ${ }^{79}$. La Red permite mantener contactos entre autoridades de distintos estados, lo que redundará en la posibilidad de debatir sobre los problemas prácticos y jurídicos en la aplicación de las normas de la $\mathrm{UE}^{80}$. La Red judicial es una entidad en el que la Comisión Europea desempeña un papel fundamental ${ }^{81}$; pero en el que también participan el Consejo y los Estados miembros ${ }^{82}$. La Comisión, además, elabora documentos que ayudan a la aplicación de los diferentes instrumentos. Así, por ejemplo, la guía práctica para la aplicación del Reglamento Bruselas II que ya ha sido citada ${ }^{83}$.

27. De acuerdo con esto, por tanto, existirán diferentes mecanismos que pueden ayudar a la aplicación armónica de los instrumentos de la UE sobre sustracción de menores. Se trata de iniciativas que facilitan la comunicación entre autoridades de diferentes estados, el intercambio de información y puntos de vista, la difusión de los problemas y la búsqueda de soluciones comunes en su resolución. Se trata de vías que se asemejan en su planteamiento a las que ya habíamos examinado en relación al Convenio de La Haya de 1980 y que pueden ir completadas por resoluciones de otras instituciones de la UE (el Parlamento, por ejemplo), recomendaciones u otro tipo de "soft law" que permitiría un diálogo constructivo entre todos los interesados que permitiría abordar las innegables dificultades que siempre tiene la aplicación de una norma sobre una diversidad de ordenamientos jurídicos que pueden partir, en ocasiones, de planteamientos muy diferentes.

\footnotetext{
${ }^{76}$ Vid. supra núm. 12.

${ }^{77}$ Título V del TFUE (Espacio de Libertad, Seguridad y Justicia), específicamente para la cooperación judicial civil, art. 81.

${ }^{78}$ Decisión del Consejo de 28 de mayo de 2001 por la que se crea una Red Judicial Europea en materia civil y mercantil (2001/470/CE), DO, núm. L 174, de 27 de junio de 2001 (puede accederse a la versión consolidada en la siguiente dirección: https://eur-lex.europa.eu/legal-content/ES/TXT/?uri=CELEX\%3A02001D0470-20110101).

${ }^{79}$ Art. 3 de la Decisión de 28 de mayo de 2001.

80 Art. 10.1.b) de la Decisión.

${ }^{81}$ La página web de la Red está mantenida por la Comisión Europea, vid. https://e-justice.europa.eu/contentPresentation. do?plang=en\&idTaxonomy $=365$.

${ }^{82} \mathrm{Vid}$., por ejemplo, el art. 12 de la Decisión

${ }^{83}$ Vid. supra n. núm. 28.
} 
De todas formas, la eficacia de estos mecanismos descansa, al menos en parte, en la posibilidad de que la Comisión u otros estados acudan al Tribunal de Luxemburgo para que este declare en última instancia que se ha producido un incumplimiento del Derecho de la UE. Esta posibilidad será un incentivo significativo para aprovechar de buena fe las facilidades que ofrecen los mecanismos de cooperación, comunicación y debate que se acaban de mencionar. A continuación, nos ocuparemos del papel del Tribunal de Luxemburgo, comenzando por su función respecto a las cuestiones prejudiciales para concluir con su papel en la declaración de incumplimiento del Derecho de la UE.

\section{El papel del Tribunal de Luxemburgo}

28. En el epígrafe anterior ya indicábamos que cuando la Comisión o un estado entienden que se ha producido el incumplimiento del Derecho de la UE cabe acudir al Tribunal de Luxemburgo para que declare dicho incumplimiento. Nos ocuparemos más delante de ello, para detenernos ahora en una función que se ha mostrado como más relevante desde una perspectiva práctica: la que realiza el Tribunal cuando responde a las cuestiones prejudiciales que le plantean los órganos jurisdiccionales de los estados miembros.

El artículo 19.3 del TUE prevé que el TJUE se pronunciará, con carácter prejudicial, sobre la interpretación del Derecho de la UE y sobre la validez de los actos adoptados por las instituciones a petición de los órganos jurisdiccionales nacionales. Esta función se desarrolla en el art. 267 del TFUE, donde se indica que la cuestión deberá responderse si es necesario para que el órgano jurisdiccional nacional pueda emitir su fallo y, además, se establece que en el caso de las cuestiones que se planeen ante un órgano jurisdiccional nacional cuyas decisiones no sean susceptibles de recurso, dicho órgano estará obligado a plantear la cuestión prejudicial al TJUE. Los arts. 93 y ss. Del Reglamento de Procedimiento del Tribunal de Justicia ${ }^{84}$ se ocupan de las particularidades del procedimiento en relación a las cuestiones prejudiciales.

29. La cuestión prejudicial permite a los órganos jurisdiccionales nacionales obtener la interpretación de las disposiciones del Derecho de la UE que sean relevantes para la resolución del caso y sobre las que tenga dudas el órgano jurisdiccional nacional. Se trata de un mecanismo que es, por tanto, esencial para conseguir una aplicación uniforme del Derecho de la UE, y no es preciso destacar su enorme relevancia en todas las materias. De hecho, el análisis de las decisiones del TJUE en la resolución de las cuestiones prejudiciales planteadas por los órganos jurisdiccionales nacionales es una parte esencial de cualquier exposición del DIPr actual en la UE.

En lo que se refiere a la aplicación de los Reglamentos que se ocupan de la sustracción de menores, hasta el momento, obviamente, solamente ha podido ocuparse del Reglamento 2201/2003, puesto que el Reglamento 2019/1111 comenzará a aplicarse a partir del 1 de agosto de 2022 (art. 105.2 del Reglamento). Ninguna decisión interpretó el precepto dedicado a la sustracción internacional de menores en el Reglamento 1347/2000 ${ }^{85}$ y en el caso del Reglamento 2201/2003 son cuatro las sentencias que se han ocupado de su art. 11, el que regula la sustracción internacional de menores ${ }^{86}$. En estas decisiones se interpretó dónde debía considerarse situada la residencia de los menores. Así, en la Sentencia de 9 de octubre de 2014 se trataba de determinar si una menor que había sido trasladada desde Francia hasta Irlanda sobre la base de una autorización judicial que posteriormente había sido anulada, conservaba su residencia en Francia o debía entenderse que esta residencia se había trasladado a Irlanda. En la sentencia de 8 de junio de 2017, el Tribunal se pronunció sobre un caso en el que una pareja había decidido que la esposa se trasladara desde Italia a Grecia con el objeto de dar a luz allí y tener la ayuda de su familia;

\footnotetext{
${ }^{84} \mathrm{https}$ //curia.europa.eu/jcms/upload/docs/application/pdf/2012-10/rp_es.pdf.

${ }^{85}$ Art. 4, vid. supra n. núm. 18.

${ }^{86}$ Sentencias de 1 de julio de 2010 (Sala Tercera), As. C-211/10 PPU, Doris Povse c. Mauro Alpago, ECLI:EU:C:2010:400, 9 de octubre de 2014 (Sala Tercera), As. C-376/14 PPU, C. c. M., ECLI:EU:2014:2268; 9 de enero de 2015 (Sala Cuarta), As. C-498/14 PPU, $R G$ c. SF, ECLI:EU:2015:3; y de 8 de junio de 2017 (Sala Quinta), As. C-111/17 PPU, ECLI:EU:C:2017:436.
} 
pero con el propósito de regresar a Italia. Tras el nacimiento, sin embargo, la niña permaneció en Grecia junto con su madre y su padre presentó una demanda de restitución al entender que no podía entenderse que la residencia de su hija se encontraba en Grecia.

En las otras dos decisiones que han interpretado el art. 11 del Reglamento 2201/2003, el Tribunal de Luxemburgo trató sobre la posibilidad de que un estado atribuya a un tribunal especializado las competencias sobre sustracción de menores ${ }^{87}$ y sobre qué decisiones han de entenderse incluidas en el art. 11.8 del Reglamento ${ }^{88}$.

30. La cuestión de la determinación de la residencia del menor es una de las cuestiones que han presentado dificultades en la aplicación del Convenio de La Haya de $1980^{89}$, por lo que el papel que puede jugar el Tribunal de Luxemburgo en la interpretación de este concepto resultará relevante; sobre todo porque no es descartable que las concreciones que se hagan, en principio a efectos exclusivos de los estados miembros de la UE, se puedan extender a otros países, dada la comunicación existente entre instrumentos y culturas jurídicas. Ahora bien, será un proceso largo ya que por vía de la cuestión prejudicial el Tribunal de Luxemburgo resuelve el problema concreto planteado y es reacio a aportar criterios que puedan ser generalizables, por lo que será preciso esperar a tener un número relevante de casos para, sobre ellos, poder realizar una construcción en relación a los problemas jurídicos que deja abiertos la aplicación de los instrumentos internacionales en materia de DIPr.

En cualquier caso, el recurso al Tribunal de Luxemburgo en la interpretación del Reglamento 2201/2003 (y en el futuro del Reglamento 2019/1111) reducirá las divergencias en la interpretación de estos instrumentos y, por tanto, también la posibilidad de que se produzcan incumplimientos de la normativa europea. Ahora bien, si se dan esos incumplimientos aún estará abierta la vía del recurso al Tribunal de Luxemburgo que se había avanzado en el epígrafe anterior y sobre el que volveremos inmediatamente.

31. Tal y como habíamos visto, los arts. 258 y 259 del TFUE prevén que tanto la Comisión como los estados miembros puedan presentar recurso ante el TJUE en el caso de que un estado no cumpla las obligaciones que le incumben de acuerdo con los Tratados. En caso de que se declare la vulneración del Derecho de la UE, el estado estará obligado a adoptar las medidas necesarias para la ejecución de la sentencia (art. 260.1 del TFUE) y si, a juicio de la Comisión, estas medidas no son adoptadas, la Comisión podrá someter el asunto al TJUE, quien podrá, a petición de la Comisión, imponer al estado el pago de una suma o una multa coercitiva (art. 260.2 del TFUE).

Es, ciertamente, poco probable que en un caso como el que nos ocupa se llegara a este punto. Sería preciso para ello que un estado siguiera una práctica contraria a lo previsto en las disposiciones sobre sustracción de menores, que pese a los intentos de reconducir la situación se mantuviera esa práctica contraria al reglamento, que no cupiera la duda de si se trataba de un punto de interpretación dudosa y que, incluso tras las observaciones de la Comisión y su dictamen, el proceso ante el Tribunal de Justicia y la sentencia que pudiera dictar éste no se produjera la modificación de la práctica. Esto es, se trataría casi de una situación de abierta rebeldía que difícilmente se prolongaría los años que duraría todo este proceso sin que se fuese corregida.

Ahora bien, lo anterior no quiere decir que la posibilidad de recurso al Tribunal de Luxemburgo deba verse como una anécdota, porque es, precisamente, dicha posibilidad de recurso la que dota de especial fuerza a todos los mecanismos previos de comunicación o cooperación. Es ese recurso último al Tribunal lo que permitirá que los mecanismos flexibles que hemos comentado en el epígrafe anterior sean especialmente efectivos. Al fin y al cabo, tal y como ya dejó escrito hace varios siglos Hobbes, "Covenants, without the sword, are but words and of no strength to secure a man at all"

\footnotetext{
${ }^{87}$ Sentencia del 9 de enero de 2015.

${ }^{88}$ Sentencia de 1 de julio de 2010 . Volveremos sobre esta decisión en el epígrafe siguiente al considerar la incidencia del Tribunal de Estrasburgo en la aplicación de los Reglamentos europeos.

${ }^{89}$ Vid. A.-L. Calvo Caravaca/J. Carrascosa GonzÁlez, "Protección de menores", loc. cit., pp. 2132-2134
} 


\section{El papel del Tribunal de Estrasburgo}

32. No podemos olvidar que también cuando se apliquen los Reglamentos europeos es posible el recurso al Tribunal de Estrasburgo, ya que los estados vinculados por el CEDH han de respetar las exigencias de éste también cuando aplican Derecho de la UE. De esta forma, los desarrollos examinados supra en el epígrafe III. 2 son también relevantes en relación al Reglamento 2201/2003 y, en el futuro para el Reglamento 2019/1111. De hecho, en la sentencia X. c. Letonia ${ }^{91}$, pese a que no resultaba aplicable el Reglamento Bruselas II bis, se introduce una referencia al mismo, manteniendo que la filosofía del Convenio de La Haya de 1980 se traslada también al mencionado Reglamento ${ }^{92}$. De hecho, tal como hemos visto, la normativa del Reglamento es complementaria de la del Convenio de La Haya, aunque refuerza los mecanismos de cooperación entre las autoridades de los estados afectados por la sustracción.

Así pues, los mismos desarrollos que habíamos considerado sobre la necesidad de acompasar la aplicación del Convenio de La Haya de 1980 a las exigencias derivadas del CEDH, y que se traducían en que no fuera ordenada la devolución del menor cuando dicha devolución no respondiera al interés superior del menor, deberán tenerse por reproducidas aquí en lo que se refiere a los Reglamentos de la UE. Ahora bien, tal como veremos a continuación, aún puede hacerse un matiz como consecuencia de la existencia del fenómeno de integración europeo.

33. El Tribunal de Estrasburgo ya se ha pronunciado en varias ocasiones sobre la compatibilidad entre las exigencias derivadas del CEDH y la existencia de un ámbito de integración como el europeo en el que los estados participantes están obligados a reducir los controles de las decisiones producidas en otros estados que participan en el mismo espacio de integración. En relación a esto, el Tribunal de Estrasburgo ha mantenido que una reducción de los controles en el estado requerido, en los supuestos de reconocimiento de decisiones adoptadas en otro Estado miembro de la UE, era admisible en tanto en cuanto todos los Estados implicados compartían un mismo sistema de tutela en origen de los derechos fundamentales ${ }^{93}$. La sentencia Povse del Tribunal de Estrasburgo ${ }^{94}$ admitió que no infringía las obligaciones derivadas del CEDH el reconocimiento de una decisión que obligaba a la restitución del menor ${ }^{95}$ en tanto en cuanto este reconocimiento respondía a las exigencias derivadas de un sistema de integración que, en su conjunto, prevé un sistema de garantías del respeto a los derechos fundamentales ${ }^{96}$. Nos encontramos, por tanto, ante otra manifestación del intento del TEDH de realizar una interpretación del CEDH que sea armónica con el resto de instrumentos internacionales que vinculan a los estados miembros del Consejo de Europa. No se descarta de manera absoluta que el TEDH pueda entrar a verificar la adecuación en la actuación de los estados miembros en aplicación de los instrumentos europeos; en concreto en aquellos casos en los que las autoridades del estado hubieran ejercido algún grado de discrecionalidad o cuando la protección de los derechos fundamentales ejercida en el estado de origen fuera manifiestamente deficiente ${ }^{97}$.

34. Los principios anteriores pueden ser trasladados a los mecanismos en caso de sustracción internacional de menores. Recordemos que en el caso Povse no se trataba propiamente de la utilización de esos mecanismos (devolución inmediata del menor o rechazo a dicha devolución por encontrarnos en alguno de los supuestos excepcionales en los que lo que mejor se adecua al interés superior del menor es permanecer en el estado al que ha sido trasladado o donde se encuentra retenido); sino del reconocimien-

\footnotetext{
${ }^{91}$ Vid. supra n. núm. 60.

${ }_{92}$ Vid. núm. 97 de la sentencia.

${ }^{93}$ Vid. sobre esto recientemente $\mathrm{M}^{\mathrm{a}} \mathrm{V}$. CUARTERo Rubio, op. cit., pp. 86-91.

${ }^{94}$ Decisión de 18 de junio de 2013, Sofia Povse y Doris Povse c. Austria, solicitud núm. 3890/11, https://hudoc.echr.coe. int/fre\# \{\%22itemid\%22:[\%22001-122449\%22]\}.

${ }_{95}$ Ya habíamos hecho referencia a la decisión del TJUE pronunciada en el mismo caso, vid. supra notas núm. 86 y 88.

${ }^{96} \mathrm{Vid}$. núm. 77 de la decisión. Sobre la doctrina en la que se basa esta decisión del Tribunal de Estrasburgo me remito a R. Arenas García, "Orden público y gobernanza multinivel”, en M.P. García Rubio/J.J. Moreso (dirs.), Conceptos multidimensionales del Derecho, Madrid, Reus/De Conflictu Legum, 2020, pp. 85-112.

${ }^{97}$ Vid. R. Arenas García, “Orden público”, loc. cit., p. 102.
} 
to en el estado en el que se encontraba el menor tras el secuestro de una decisión adoptada en el estado en el que el menor tenía su residencia antes del traslado ilícito, que ordenaba el retorno del menor. En este caso, el reconocimiento, obligado de acuerdo con lo previsto en el Reglamento 2201/2003, tal como lo había interpretado el Tribunal de Luxemburgo, no fue considerado contrario a los derechos protegidos por el CEDH.

En un caso típico de sustracción, el retorno del menor ordenado por la autoridad del estado al que hubiera sido trasladado, de acuerdo con las exigencias que se recogen en los Reglamentos europeos no debería, en principio, ser considerada contraria a lo establecido en el CEDH según la doctrina que se acaba de exponer; pero no podemos perder de vista que, como se ha indicado, en los casos en los que el estado haya ejercido algún tipo de discrecionalidad, sí será posible dicho control. En el caso de la sustracción internacional, y pese a que, como ya se ha examinado, en el ámbito europeo se ha reducido el margen de esa discrecionalidad, siempre habrá un margen de apreciación por parte de las autoridades del estado en el que se encuentra el menor, por lo que no cabrá excluir totalmente, ni siquiera en el marco de integración que configura la UE, el recurso al Tribunal de Estrasburgo para que, en última instancia, determine si la aplicación de los instrumentos sobre sustracción internacional de menores supone una vulneración del CEDH.

\section{Conclusión}

35. En ocasiones no es fácil establecer la distinción entre las dificultades de interpretación y aplicación que supone todo texto internacional destinado a ser utilizado en varios países, de lo que sería un incumplimiento de dicho texto. En el caso de los principales instrumentos sobre sustracción internacional de menores hemos de diferenciar entre el Convenio de La Haya de 1980 y los Reglamentos de la UE. En el caso del primero, tan solo un más que improbable recurso al TIJ permitiría que una autoridad que se sitúa por encima de todos los estados implicados, determinara de manera definitiva si se había producido o no un incumplimiento del instrumento. Por lo que se refiere a los Reglamentos de la UE la situación es completamente diferente ya que gozan de todos los mecanismos de aseguramiento con los que cuenta el Derecho de la Unión. Aún así, el recurso a los mecanismos existentes para declarar el incumplimiento por parte de un Estado del Derecho de la UE no es probable que se de, ya que existen vías anteriores a esta declaración que pueden resolver de una manera más eficaz las disfunciones que se derivan de la aplicación de los mencionados instrumentos en varios estados.

No obstante lo anterior, es necesario destacar que la existencia de esos mecanismos facilitará la eficacia de otros que se basan en la comunicación entre autoridades, la difusión de las dificultades existentes y la búsqueda de soluciones. Estos mecanismos no permitirán resolver los concretos incumplimientos de la normativa que puedan darse, pero facilitarán una interpretación armónica de la misma en los diferentes países. La Conferencia de La Haya de DIPr. también recurre a estos mecanismos flexibles para poner de relieve los incumplimientos de los instrumentos relevantes (calificados con frecuencia como "dificultades" o "problemas" en vez de incumplimientos).

36. El Tribunal de Estrasburgo se ha convertido en una instancia con capacidad para resolver algunos de los problemas derivados de la inaplicación de los instrumentos en materia de sustracción internacional de menores. Pese a que el TEDH no tiene como función velar por el cumplimiento de los convenios internacionales aparte del CEDH, el hecho de que la sustracción implique una perturbación de la vida personal y familiar habilita al TEDH para verificar que se han empleado adecuadamente los instrumentos existentes para restaurar la situación familia. El TEDH también puede operar tanto cuando ha de aplicarse el Convenio de La Haya de 1980 como cuando la normativa relevante son los Reglamentos de la UE; aunque en este caso de forma más limitada.

Otros mecanismos de Derecho internacional público como son la protección diplomática o el recurso al TIJ carecen de virtualidad práctica en relación a esta materia. 